\title{
Relaxation of Geothermat-Reservoir Stresses Induced by Heat Production
}
H. Murphy, Editor
R. Aamodt
H. Keppler*
H. Fisher
C. Pearson
T. Grant
R. Potter
C. Grigsby
G. Suhr**
R. Hendron
G. Zyvoloski

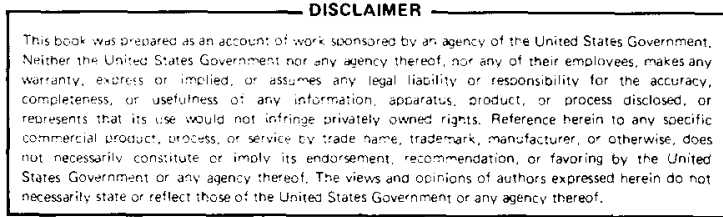

*Alien Guest Scientist. Federal Institute for Geosciences and National Resources (B.G.R.), Hannover, FEDERAL REPUBLIC OF GERMANY.

**Alien Guest Scientist. Prakla-Seismos, Hannover, FEDERAL REPUBLIC OF GERMANY. 


\section{DISCLAIMER}

This report was prepared as an account of work sponsored by an agency of the United States Government. Neither the United States Government nor any agency Thereof, nor any of their employees, makes any warranty, express or implied, or assumes any legal liability or responsibility for the accuracy, completeness, or usefulness of any information, apparatus, product, or process disclosed, or represents that its use would not infringe privately owned rights. Reference herein to any specific commercial product, process, or service by trade name, trademark, manufacturer, or otherwise does not necessarily constitute or imply its endorsement, recommendation, or favoring by the United States Government or any agency thereof. The views and opinions of authors expressed herein do not necessarily state or reflect those of the United States Government or any agency thereof. 


\section{DISCLAIMER}

Portions of this document may be illegible in electronic image products. Images are produced from the best available original document. 
RELAXATION OF GEOTHERMAL RESERVOIR STRESSES INDUCEN BY HEAT PRODIJCTION

by

H. Murphy (Ed.), R. Aamodt, H. Fisher, T. Grant, C. Grigsby, R. Hendron, H. Keppler, C. Pearson, R. Potter, G. Suhr, and G. Zyvoloski

\section{ABSTRACT}

Fifteen million kWh of thermal energy were produced during 281 days of operation of the hot dry rock (HDR) geothermal reservoir at Fenton $\mathrm{Hill}$, New Mexico. Following this heat production the thermal stresses and strains so induced were partially released by a short, 7 -h pressurization of the reservoir above the local tectonic confining stress. Following the partial stress release, it was found that the resistance to water flow through the reservoir was decreased by $37 \%$, and that the reservoir volume, as measured by tracer studies, increased by $43 \%$. Microseismic events recorded with geophones in two deep wells at positions within a few hundred meters of the reservoir were concentrated in those regions of the reservoir most affected by thermal depletion. These events define a reservoir region and size in qualitative agreement with estimates based upon heat production modeling.

\section{INTRODUCTION}

On December 9 and 10, 1980, after 281 days of sustained heat extraction that took place during Run Segment 5, the stress unlocking experiment (SUE) was conducted. Run Segment 5 was the latest in a series of tests of the hot dry rock (HDR) geothermal reservoir at Fenton Hill, in the Jemez Mountains of northern New Mexico. The results of Run Segment 5, as well as a general description and historical background of the HDR geothermal project are reported in Ref. 1. The stress unlocking experiment had four purposes: 
(1) Produce acoustic signals, that is, microseismicity from the produced geothermal reservoir by releasing the accumulated thermal strains and stresses produced by 281 days of sustained heat extraction and rock cooling. At the time of the SUE experiment about $15000000 \mathrm{kWh}$ of thermal energy had been extracted from the reservoir. The relaxation of thermal stresses was accomplished by pumping water in the reservoir injection we11, EE-1, at high pressures, about $15 \mathrm{MPa}$ (2200 psi). Because the reservoir production wel1, GT-2B, was shut-in, or also pressurized, nearly the entire reservoir was pressurized to high levels, and it was hoped that the normal forces that held the fracture faces together in frictional contact would be reduced, resulting in shear slippage and microseismicity. Monitoring of microseismic signals was performed with two downhole geophone packages, one stationed in GT-2B (the usual reservoir production well) and the other in EE-2 (a recently drilled well) that served as an observation well for this experiment.

(2) Reduce the fracture flow impedance as a consequence of the shearslippage of fracture faces.

(3) Provide the first cycle of a Huff-Puff mode of reservoir heat extraction. The usual mode of heat extraction is a steady-flow-circulation mode in which flow is injected at a constant rate in the injection well and withdrawn steadily at the production well. The heat extraction in this mode is limited by the fluid streamline patterns and may not reflect the heat extraction potentially available from the total fracture area. Huff-Puff operation is cyclical. Fluid is first injected without withdrawal, thus inflating the fractures, and after a thermal "soak" time the fluid is then withdrawn.

(4) Investigate the possibility of studying changes in reservoir spectral pressure responses due to increased reservoir size or reduced flow impedance.

Pumping at the flow rates and pressure levels intended for SUE was beyond the Los Alamos circulating pumps. Consequently, pumping services were rented from the Halliburton Company for the occasion. One low-pressure pump truck, normally used for blending purposes, and three high-pressure pump trucks, usually used for fracturing operations, were provided. The cost of renting this equipment, and the operators required to man the equipment, was $\$ 13300$. Only one high-pressure truck was actually required, the other two remained on standby. The pump trucks were arranged so that the blender took water from the GT-2B pond and the so-called "black" storage tank, which holds $150 \mathrm{~m}^{3}$ 
(40 $000 \mathrm{gal}$ ). The blender was connected to the black tank, and water was transferred from the pond to this tank by the Los Alamos "supercharger" pump. This water was then pumped to the high-pressure pump, which raised the pressure and injected the water into either EE-1 or GT-2B, depending upon the phase of the experiment. The high-pressure pump was plumbed into the loop piping near the EE-1 wellhead, just upstream of flow control valve 1 . Injection flow rates were measured with a Halliburton-supplied 4-in. turbine flow meter.

SUE consisted of three main phases: (1) injection into EE-1, (2) injection into GT-2B, and (3) venting from GT-2B. A fourth phase, the impedance measurement immediately following SUE, was technically not a part of SUE, but the results of this measurement are included in this report for completeness. Phase (1), EE-1 pumping with the Halliburton trucks, started at about 15:00 on December 9. This initial Halliburton pumping was conducted at $0.0074 \mathrm{~m}^{3} / \mathrm{s}$ (118 gpm), corresponding to the usual circulating rate that prevailed in Run Segment 5 just prior to SUE; the purpose was simply to switch from Laboratory to Halliburton pumping as smoothly as possible and reestablish typical Run Segment 5 conditions prior to the first high-flow-rate step of Phase 1 . This switch in pumping systems and the subsequent pumping steps are shown in Fig. 1 . The first high-rate pumping step began at $16: 00$ at $0.013 \mathrm{~m}^{3} / \mathrm{s}$ (210 gpm), and as shown in Fig. 1, was succeeded by two more steps at 0.027 and 0.047 $\mathrm{m}^{3} / \mathrm{s}(420$ and $750 \mathrm{gpm})$. In the sustained EE-1 pressurization that followed the $0.047-\mathrm{m}^{3} / \mathrm{s}$ step, the flow rate was adjusted slightly, to a final value of $0.042 \mathrm{~m}^{3} / \mathrm{s}(660 \mathrm{gpm})$, roughly in balance with the less-than-expected pumping capacity of the supercharger pump that transported water from the GT-2B pond to the black tank. Following the injection volume of $1000 \mathrm{~m}^{3}$ (270 000 gal), the planned amount, EE-1 was shut in at 23:00 and Phase (2), injection into GT-2B at approximately $0.026 \mathrm{~m}^{3} / \mathrm{s}(420 \mathrm{gpm})$, was started. The GT-2B flow was injected through the buried 73-mm (2-7/8-in.) pipe from the EE-1 area to the GT-2 wellhead. An increase of pumping rate to $0.030 \mathrm{~m}^{3} / \mathrm{s}$ was accomplished about hal fway through the planned $38-\mathrm{m}^{3}$ (10 000-gal) GT-2B injection. Just as the end of the total GT-2B injection was approached, piping vibrations were noted at GT-2B, and Halliburton flow jumped to $0.069 \mathrm{~m}^{3} / \mathrm{s}(1090 \mathrm{gpm})$. No such gyrations were recorded in the CDA. Pumps were shut down immediately at 23:23. Maximum GT-2B pressure during the injection was $13 \mathrm{MPa}$ (1890 psi). At $23: 24$, following the injection of the $38 \mathrm{~m}^{3}$, GT-2 was shut in. 


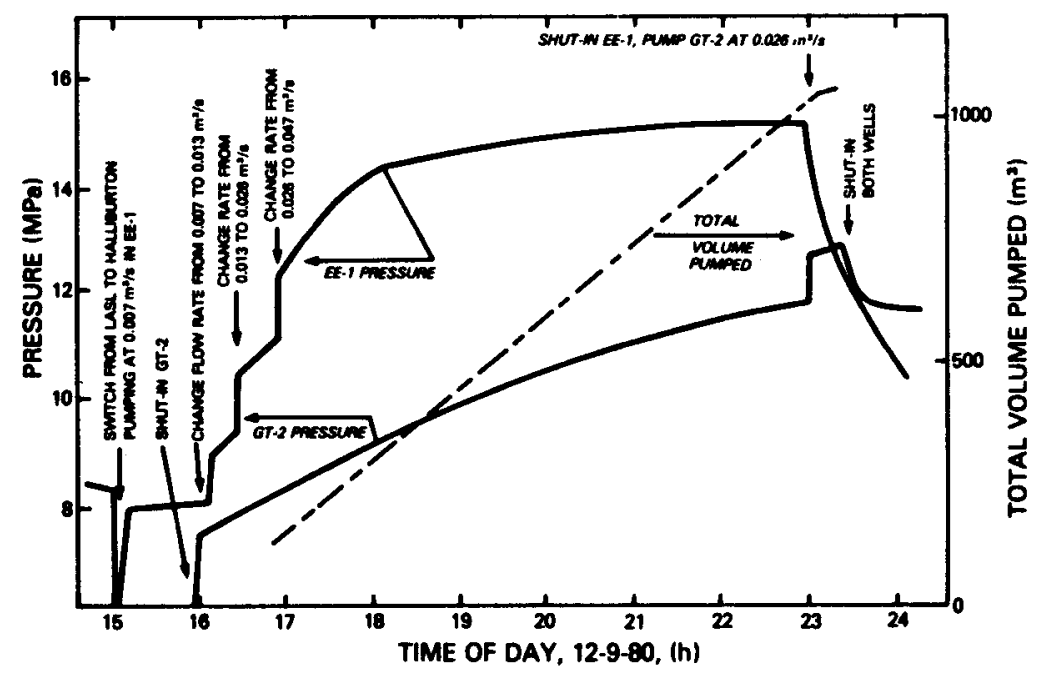

Fig. 1 .

Major system parameters during SUE.

The GT-2B injection volume was limited to $38 \mathrm{~m}^{3}$ to avoid significant thermal perturbation to the normally hot production well, which could have resulted in damage to the casing cement. The EE-1 injection was limited to $1000 \mathrm{~m}^{3}$ because the combined injections, about $1040 \mathrm{~m}^{3}$, were equal to the total storage capacity in the GT-2B pond and the black tank. Following the GT-2B shutin, the pressure in both wells decreased slowly.

Phase (3), the vent from both GT-2B and the continuing leak from the EE-1 annulus, was started on 12-10-80 at 00:47. The flow rate from GT-2B varied from 0.012 to $0.014 \mathrm{~m}^{3} / \mathrm{s}(190$ to $220 \mathrm{gpm})$ as the control valve $\mathrm{FCV}-2$ was periodically opened. Seismic monitoring was terminated at 00:52 and the geophone tool was removed from EE-2. The GT-2 tool was raised at 03:30 to $55 \mathrm{~m}$ (180 $\mathrm{ft}$ ) and parked with the arm extended. The loop was readied for easy change from vent to circulating mode at the same time. Venting was first run through the temporary surface transfer line from the EE-1 area to the GT-2 pond. Initial venting seemed to indicate a very quick pressure drop and return to loop operations and impedance testing. By the time loop preparations were made the pressures were decreasing slowly and venting continued into EE- 1 pond and then to GT-2 pond. At $04: 16$ the flow rate dropped below $0.013 \mathrm{~m}^{3} / \mathrm{s}$ and the GT-2B control valve was opened all the way. By 06:00 the EE-1 pressure was $8.3 \mathrm{MPa}(1200 \mathrm{psi})$; GT-2B was $1.1 \mathrm{MPa}(165 \mathrm{psi})$ and venting at $0.012 \mathrm{~m}^{3} / \mathrm{s}$ $(180 \mathrm{gpm})$. The annulus flow rate was $0.002 \mathrm{~m} / \mathrm{s}(30 \mathrm{gpm})$. The wellhead 
pressures were thus approximately those prevailing prior to the SUE injections, so closed-loop operation was reestablished at 06:20, December 10, in order to measure the post-SUE impedance. The system operated while venting through the EE-1 annulus and FCV-3 with no make-up until 07:45, December 11 . Loop-operating data then provided information for an impedance calculation. On Thursday, December 11, the system was shut in from 13:00 to 14:50 to change pump seals for the final $\mathrm{NH}_{4} \mathrm{Br}^{82}$ tracer experiment of Segment 5 . The tracer was injected in EE-1 at 12:50, December 12 and monitored in EE-1 until 23:14, December 14. A spinner/temperature survey in GT-2B was performed on December 15. The $\mathrm{NH}_{4} \mathrm{Br}$ concentration in the fluid produced from GT-2B was monitored until 1oop shut-down, which occurred on December 16, 1980 at 09:00.

During SUE the annulus leak flow rate at $E E-1$ increased from $0.0015 \mathrm{~m}^{3} / \mathrm{s}$ (24 gpm) at the beginning of the experiment to a maximum of $0.0037 \mathrm{~m}^{3} / \mathrm{s}$ (59 $\mathrm{gpm})$; the maximum occurred about 18 min after cessation of the injection into GT-2B.

Analyses of the EE-1 and GT-2B pressure rises that accompanied the injection rate steps of phases (1) and (2) are described in the next main section. Also found in this section are analyses of the vent, phase (3), and implications for the Huff-Puff mode of heat extraction with the reservoir. Following these pressure-transient analyses is a preliminary report on the microseismic observations during the pressurization phases (1) and (2) and another section dealing with the pressure oscillations. This is then followed by our analysis of impedance and fracture volume changes caused by SUE. The final section lists our conclusions.

\section{PRESSURE-TRANSIENT ANALYSES}

The pressure data used in this section are all raw data and are not corrected for buoyancy. In Sec. $V$, in which buoyancy corrections are important for impedance determinations, such corrections are incorporated.

A. Phase (1), EE-1 Injection

The EE-1 flow rates and pressures for each of the high-flow-rate steps are plotted in detail for each flow step in Figs. 2, 3, and 4. In Fig. 2 the flow data are somewhat sparse because of a transducer malfunction and in fact some of the data were transmitted by the Halliburton operator. The pressure response to the flow steps indicates a fairly complex system. However, a few tentative findings can be reported. 


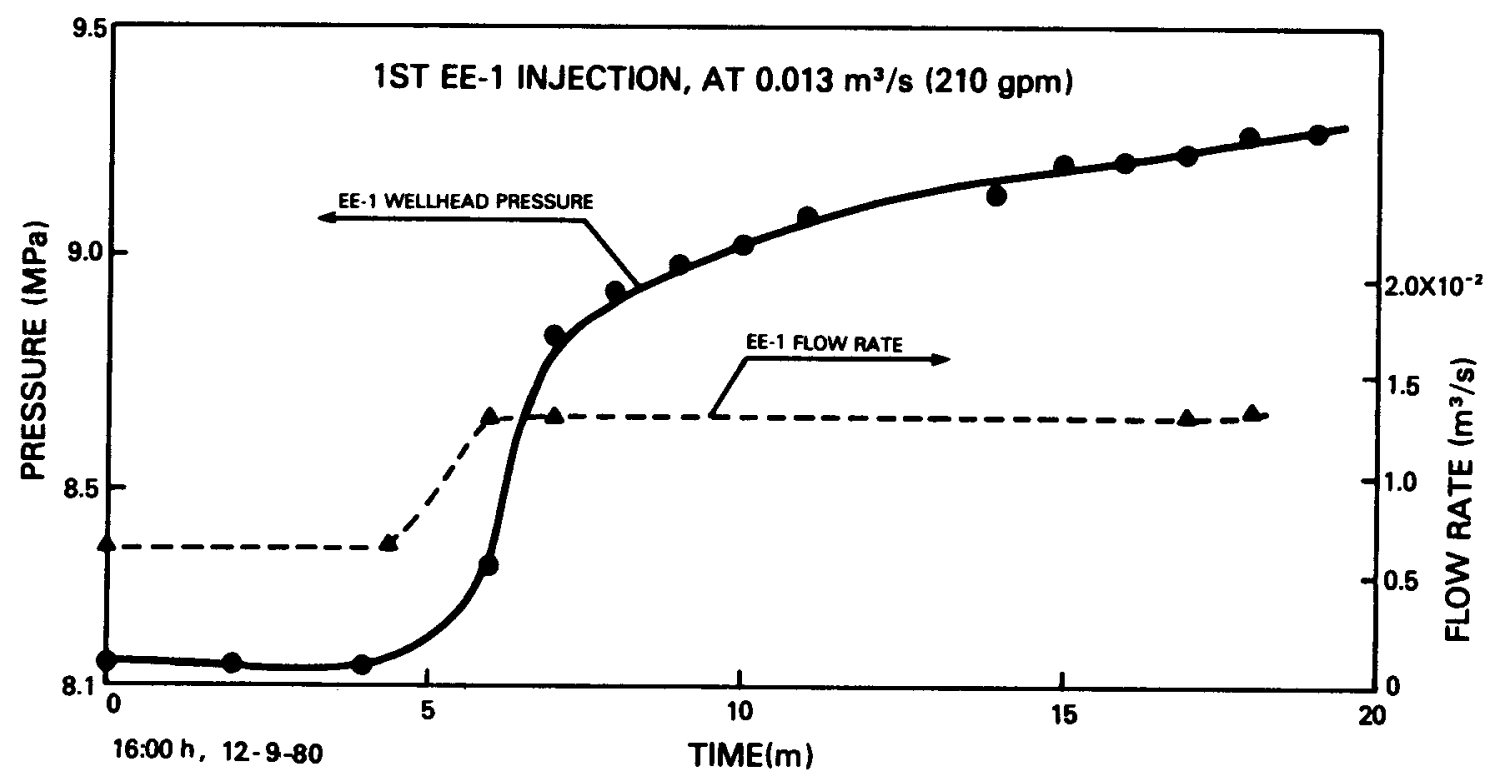

Fig. 2.

EE-1 pressure and flow rate during first EE-1 injection.

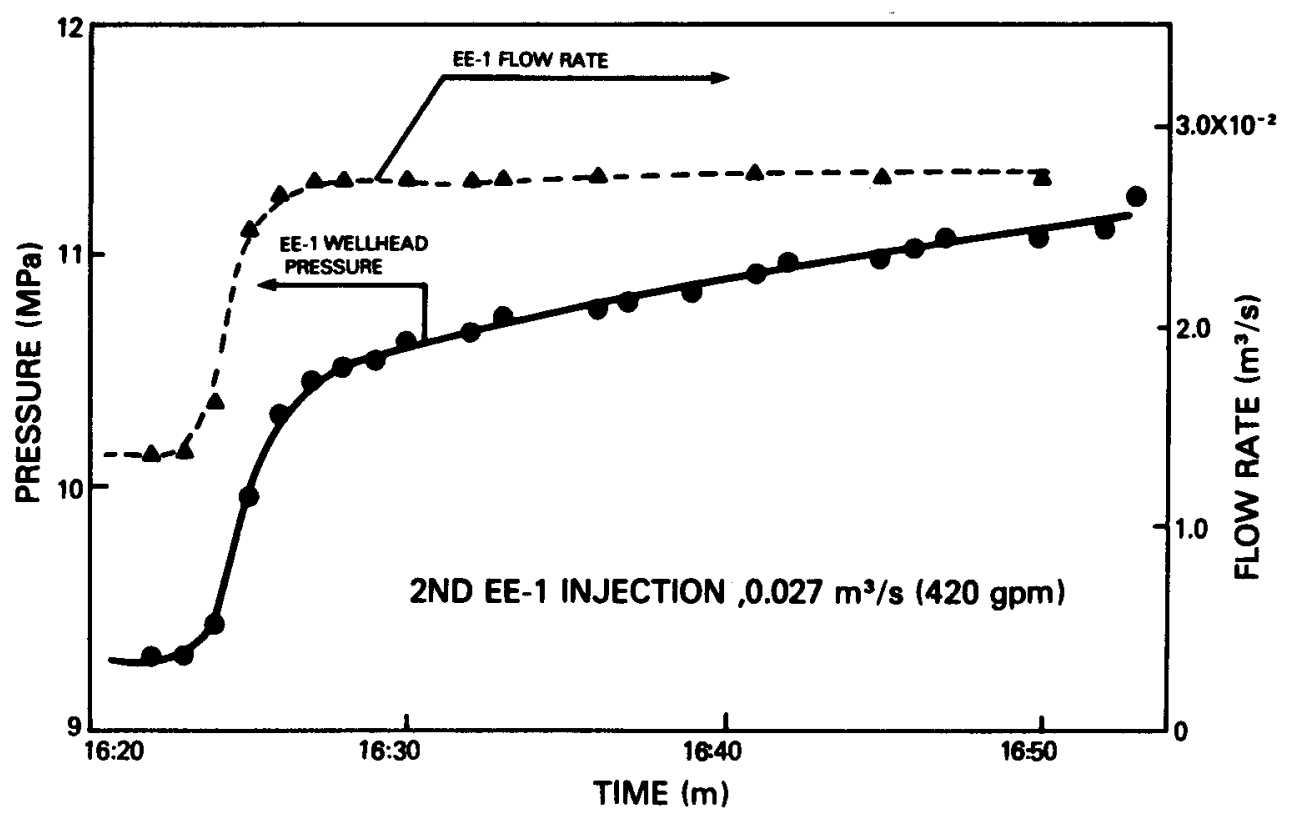

Fig. 3 .

EE-1 pressure and flow rate during second EE-1 injection. 
Each pressure response has a rapid initial rise that corresponds to the increase of flow rate. This can be attributed to an input impedance located near the EE-1 wellbore. The resulting input-impedance values are plotted in Fig. 5 as a function of the starting pressure at the beginning of each flowrate step. These values also probably contain some flow dependence. In Figs. 2, 3, and 4 each rapid rise of pressure is followed by a period in which the pressure increase is approximately proportional to the square root of time. This defines a receptivity (Ref. 1) that is also plotted in Fig. 5. There is no particular correlation with pressure. However, this interpretation of the data is not unique and the diffusion receptivity is also a function of flow rate.

B. Phase (2), GT-2B Injection

Starting at 23:00, December 9, EE-1 was shut in and we began injection into $\mathrm{GT}-2 \mathrm{~B}$ at the rate of $0.026 \mathrm{~m}^{3} / \mathrm{s}(420 \mathrm{gpm})$ for approximately 25 minutes. The resulting pressure response is plotted in Fig. 6. The entrance impedance at $G T-2 B$ was reduced to about $20 \mathrm{MPa} \mathrm{s} / \mathrm{m}^{3}(0.2 \mathrm{psi} / \mathrm{gpm})$ by the high resulting GT-2B pressure. This impedance value pertains only to operation with GT-2B at the pressures shown, about $12 \mathrm{MPa}$ (1700 psi). Such a pressure would represent an extreme case of "high-back-pressure" (HBP) operation. Operation at more normal, low back pressure (LBP) of about $1.4 \mathrm{MPa}(200 \mathrm{psi}$ ) would result in additional fracture closure. As will be seen in Sec. $V$, this closure results in a LBP impedance of $0.6 \mathrm{GPa} \mathrm{s} / \mathrm{m}^{3}(5.5 \mathrm{psi} / \mathrm{gpm})$. Although high in comparison to HBP operation, this LBP exit impedance is still about one-half what it was before SUE.

C. Phase (3), The GT-2B Vent

Figures 7 and 8 show the details of the pressure and flow histories during the shut-in of both wells prior to the GT-2B vent and during the vent itself. Actually shown in Fig. 8 is the EE-1 annulus leak rate, which, as mentioned in the introduction, reached a maximum of $0.0037 \mathrm{~m}^{3} / \mathrm{s}$ (59 gpm) during the shut-in. During the vent a total of $345 \mathrm{~m}^{3}$ (91 000 gal) of water was recovered. Of this, $270 \mathrm{~m}^{3}$ was recovered at GT-2B and $75 \mathrm{~m}^{3}$ was recovered from the EE-l annulus.

After the beginning of the vent at 00:47 on December 10, the GT-2B pressure decreased nearly linearly with time as the GT-2B control valve was opened to maintain a flow of 0.012 to $0.014 \mathrm{~m}^{3} / \mathrm{s}$. After the GT-2B pressure reached $1.4 \mathrm{MPa}$ and was maintained at this value, the GT-2B flow decreased slowly to 


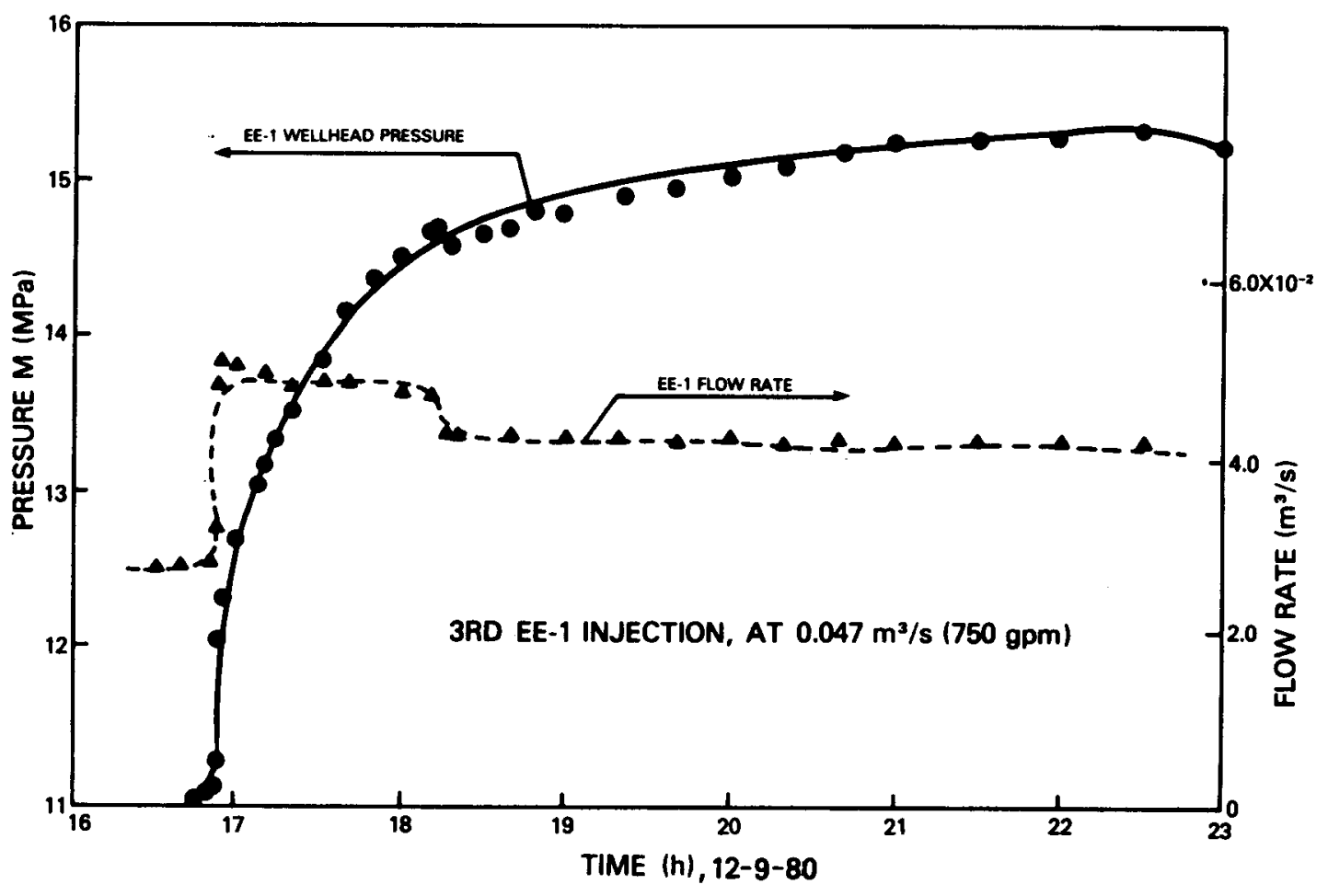

Fig. 4 .

EE-1 pressure and flow rate during third EE-1 injection.

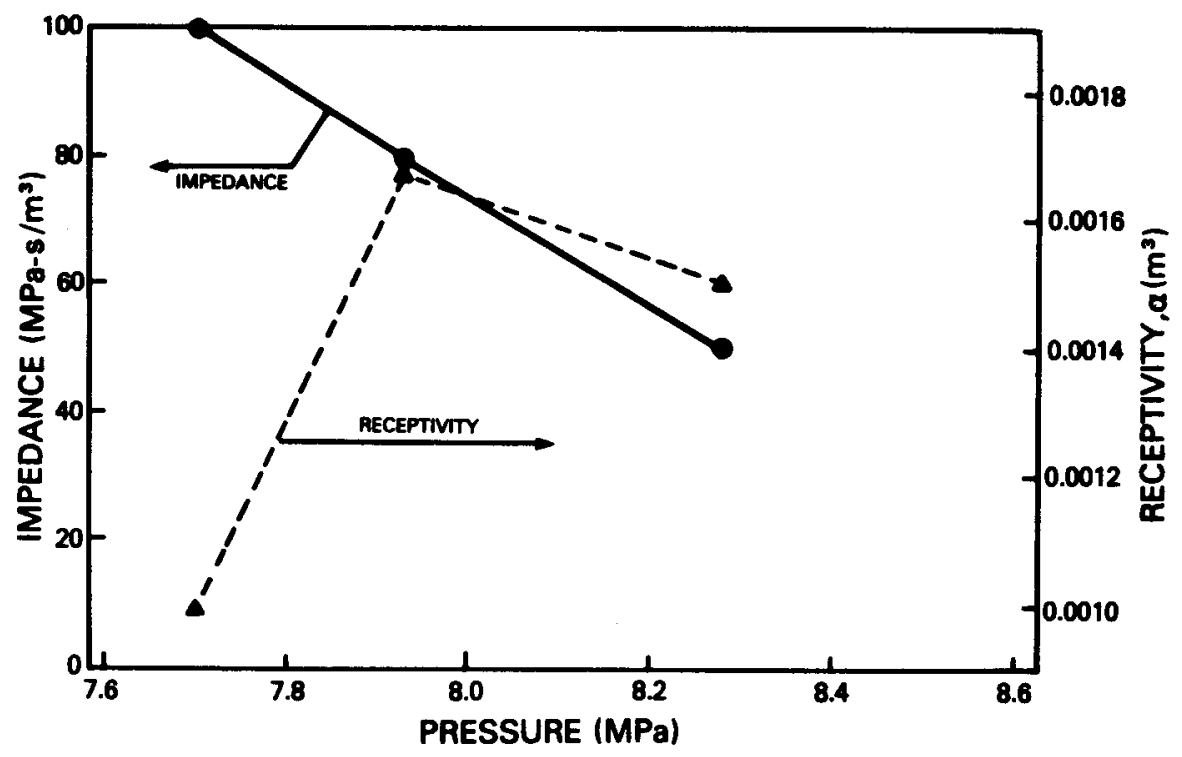

Fig. 5 .

EE-1 input impedance and receptivity. 


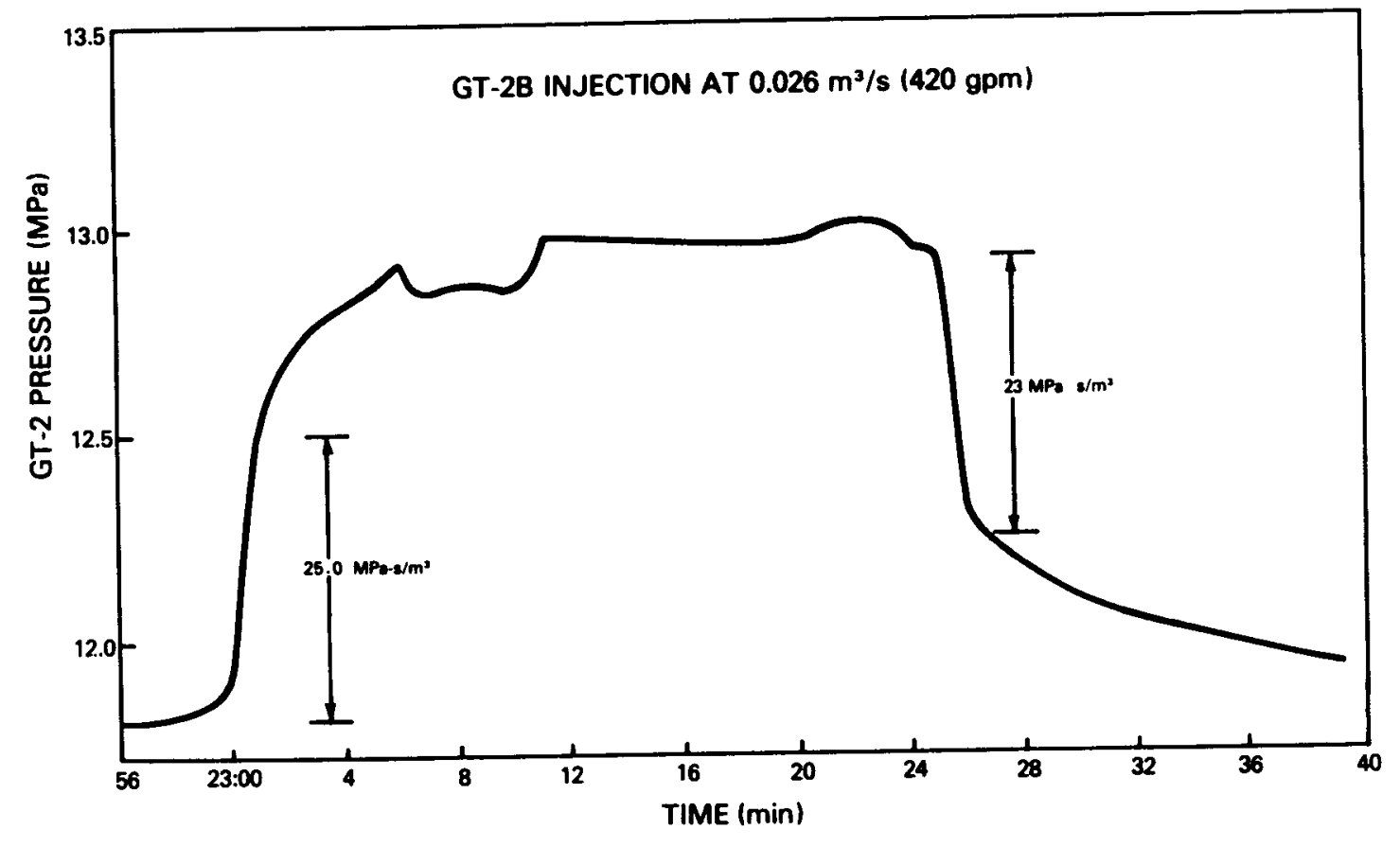

Fig. 6.

GT-2B pressure during $G T-2 B$ injection.

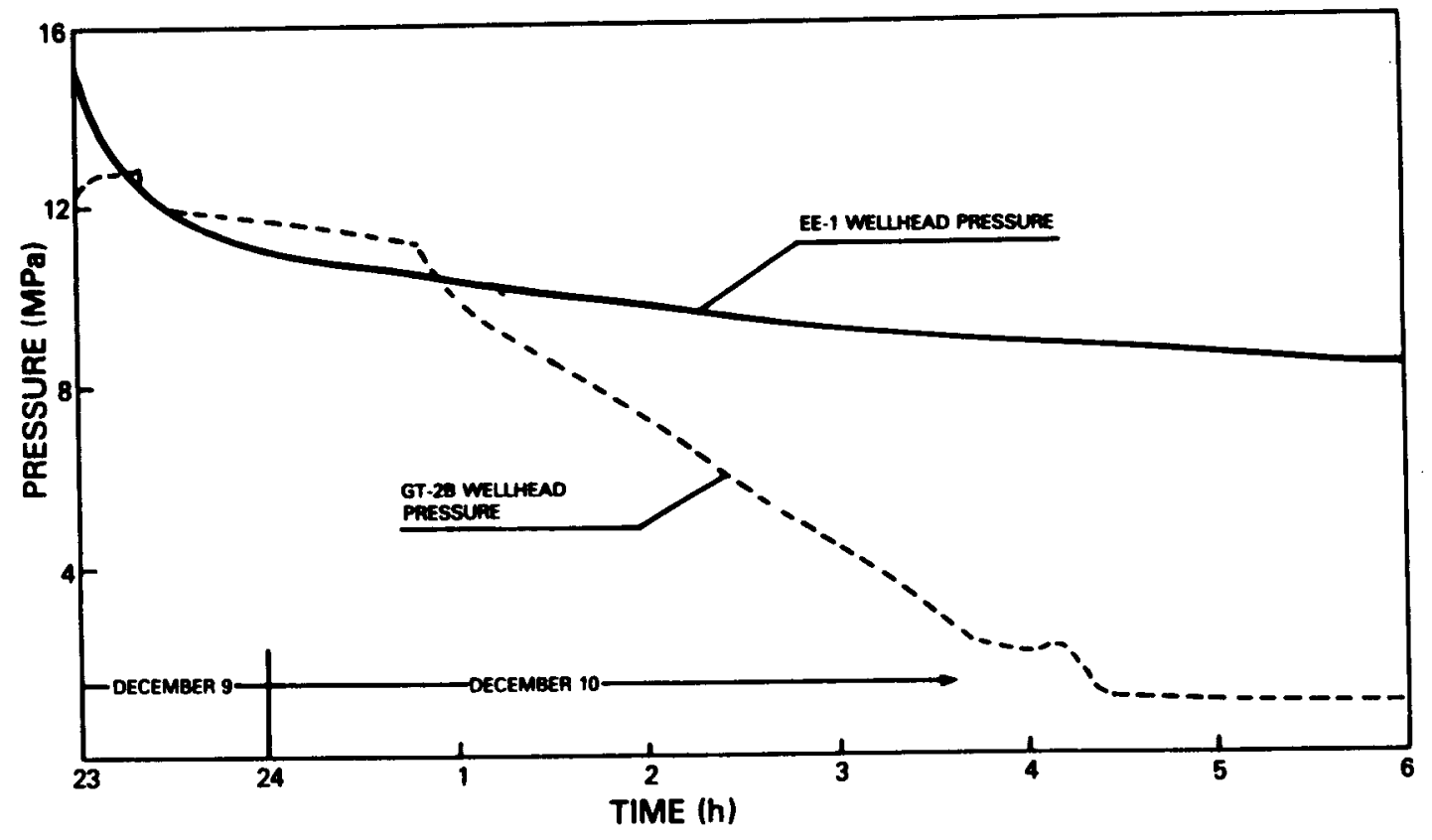

Fig. 7.

Wellhead pressures during shut-in and vent. 


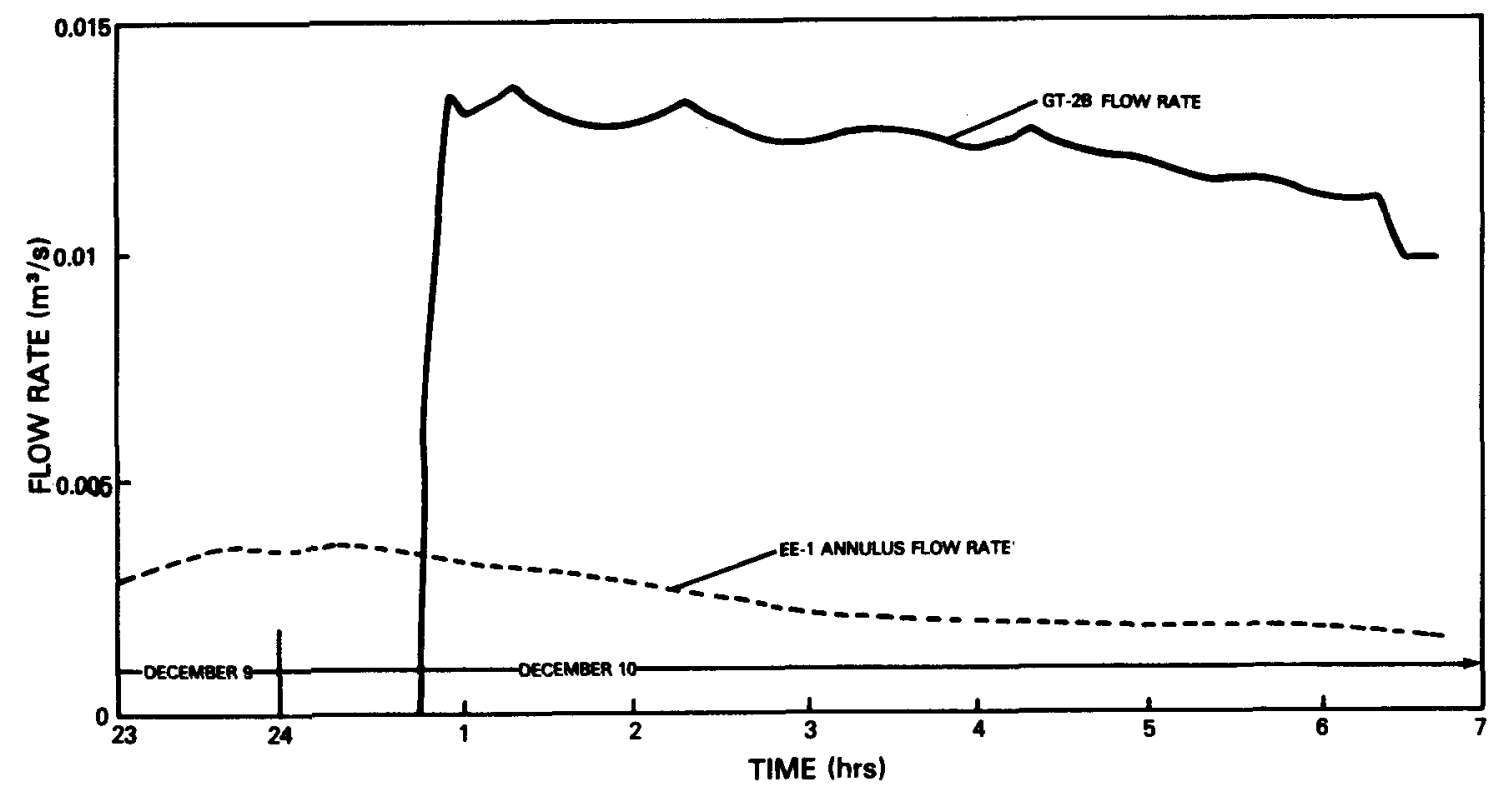

Fig. 8 .

Flow rates during shut-in and vent.

$0.011 \mathrm{~m}^{3} / \mathrm{s}$. This gradual decrease of the GT-2B pressure, $P_{2}$, and almost constant GT-2B flow, $Q_{2}$, can be explained in terms of a simple pressure dependence of exit impedance $I_{2}\left(P_{2}\right)$. The argument, $P_{2}$, of the exit impedance expresses concretely the above concept that $I_{2}$ is a function of $P_{2}$. The exit impedance at LBP $\left(P_{2} \backsim 0\right)$ is designated as $I_{2}(0)$. If we assume that the slow decay of both $P(E E-1)$ and $P_{2}$ during the shut-in means that the reservoir pressure $\left(P_{R}\right)$ does not decrease rapidly during the vent, then

$$
I_{2}(P)=\frac{P_{R}-P_{2}}{Q_{2}} \text {. }
$$

Because $Q_{2}$ was observed to remain roughly constant and $P_{R}$ is assumed constant, Eq. (1) can be rewritten in the form

$$
I_{2}(P)=I_{2}(0)\left(1-\frac{P_{2}}{P_{r}}\right)
$$

Using the data from the vent in Eq. (2), it can be shown that

$$
\mathrm{I}_{2}(0)=0.84 \mathrm{GPa} \mathrm{s} / \mathrm{m}^{3}(7.5 \mathrm{psi} / \mathrm{gpm}) \text { and } \mathrm{P}_{r}=10 \mathrm{MPa} \text {. }
$$


This value of LBP exit impedance, $\mathrm{I}_{2}(0)=0.84 \mathrm{GPa} \mathrm{s} / \mathrm{m}^{3}$, compares favorably with the value $0.6 \mathrm{GPa} \mathrm{s} / \mathrm{m}^{3}$ obtained in the usual loop operatina manner during the impedance measurement following SUE (see Sec. V). The pressure dependency of $I_{2}(P)$ was determined from the vent data and $E q .(1)$ and is compared in Fig. 9 with other measurements made immediately before. This linear dependence of impedance on pressure has been observed previously (Refs. 1 and 2) and is discussed in detail in Ref. 1.

D. Huff-Puff Implications

The inflation and vent of the system was also used to evaluate those characteristics of the system that would affect two-port huff-puff operation. of particular interest are the water loss per cycle, the vent volume, and the

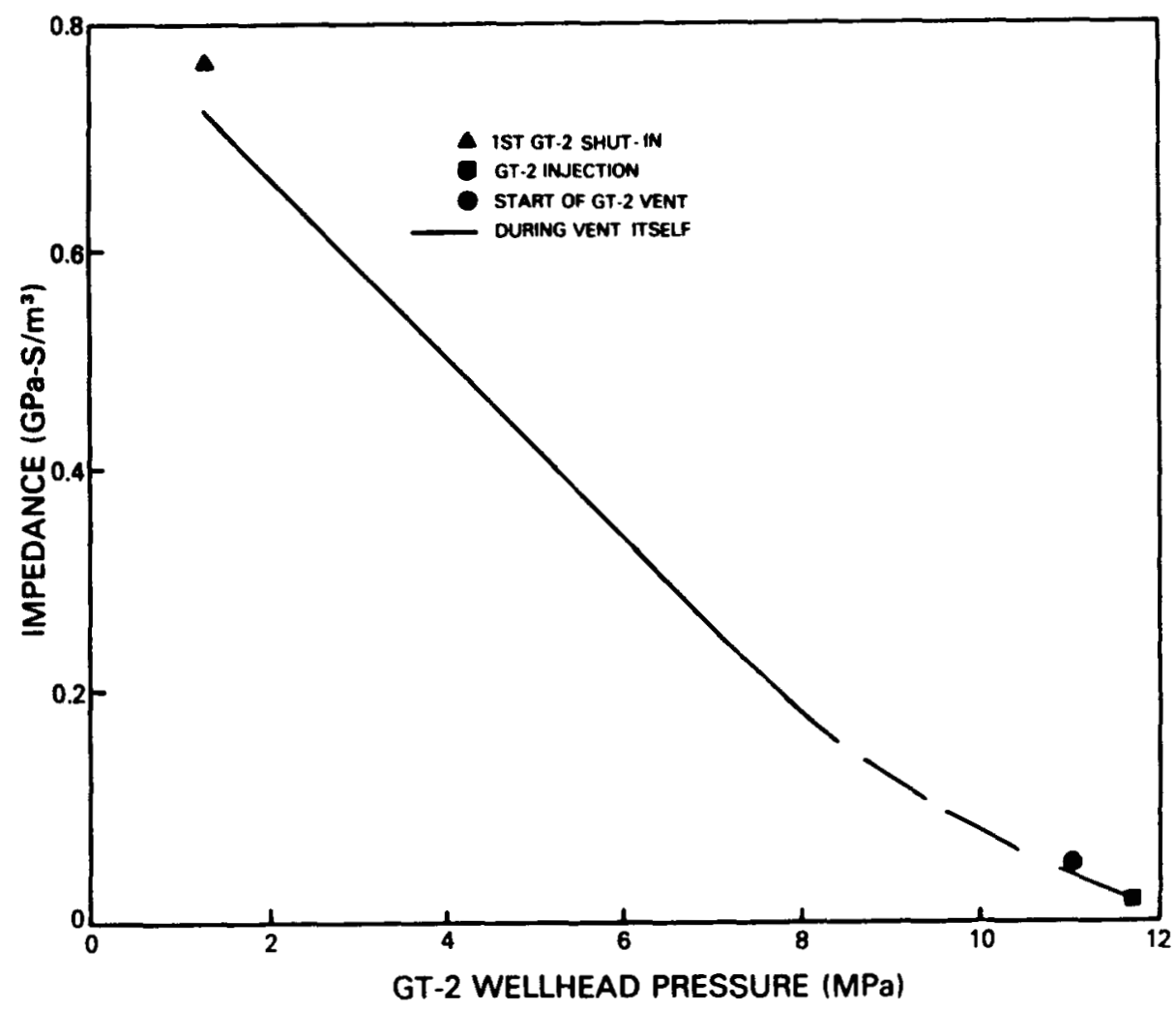

Fig. 9.

Approximate dependence of GT-2B outlet impedance upon GT-2B wellhead pressure. 
average venting flow rate. The single huff-puff cycle of the experiment can be viewed in two ways. In mode $I$, it can be considered a complete early cycle of a high-pressure operation in which the EE-1 pressure is to oscillate about a pressure of $12 \mathrm{MPa}$ (1700 psi), which is substantially greater than the usual operating pressure of $8 \mathrm{MPa}(1200 \mathrm{psi})$ at which the water losses were satisfied during Run Segment 5 . In mode II, it can be considered part of a lowpressure operation, of which only part of the vent cycle is present. The vent cycle was terminated to allow time for the subsequent impedance measurement, in which quasi-steady conditions were desired for a high-quality measurement. For mode I the EE-1 pressure would oscillate about an intermediate value of 8 $\mathrm{MPa}$, for which the water losses have been completely satisfied. Even though the vent was terminated prematurely, the vent flow rate can be extrapolated to give approximate vent duration and flow rates. A linear extrapolation of the flow rate from the existing data (Fig. 8) will give lower limits to the vent duration, flow rate, and vent volume. The results of this extrapolation are included in Table I with the important parameters for both mode I and mode II operation.

It can be seen from this summary that both modes have reasonable cycle lengths and high average-vent-flow rates that are necessary for the operation of a huff-puff system. The estimated water losses are consistent with the pressurization state of the reservoir and can be expected to decline in the same manner as in the flow-through experiments.

\section{MICROSEISMIC OBSERVATIONS}

The SUE experiment has provided a new series of microseismic events that were released by increased pressurization of the EE-1/GT-2B fracture system. For the first time this type of activity was monitored by two widely separated downhole-triaxial-geophone stations [at $2697 \mathrm{~m}(8850 \mathrm{ft})$ in GT-2B, and $2918 \mathrm{~m}$ (9575 ft) in EE-2, true vertical depth]. Initial estimates indicate that over 15000 events (detected and recorded at both stations) were caused by the $7 \mathrm{~h}$ of pressurization. None of these events were large enough to be detected by the surface seismic systems even though these experienced low background activity during the pressurization. 
TABLE I

HUFF-PIIFF CHARACTERISTICS

\begin{tabular}{|c|c|c|c|c|}
\hline & & & $\begin{array}{c}\text { Mode I } \\
\text { High Pressure }\end{array}$ & $\begin{array}{c}\text { Mode II } \\
\text { Low Pressure } \\
\end{array}$ \\
\hline \multirow[t]{2}{*}{$\begin{array}{l}\text { Pressures } \\
\text { (MPa) }\end{array}$} & $\mathrm{EE}-1$ & $\begin{array}{l}\text { Max } \\
\text { Ave } \\
\text { Min }\end{array}$ & $\begin{array}{r}15.2 \\
11.7 \\
8.3\end{array}$ & $\begin{array}{r}15.2 \\
6.9 \\
3.5\end{array}$ \\
\hline & GT -2 & $\begin{array}{l}\text { Max } \\
\text { Ave } \\
\text { Min }\end{array}$ & $\begin{array}{r}12.4 \\
6.9 \\
1.5\end{array}$ & $\begin{array}{r}12.4 \\
10 \mathrm{w} \\
1.5\end{array}$ \\
\hline \multirow[t]{3}{*}{$\begin{array}{l}\text { EE-1 } \\
\text { Injection }\end{array}$} & & $\begin{array}{c}\text { Flow rate } \\
\left(\mathrm{m}^{3} / \mathrm{s}\right)\end{array}$ & $4.1 \times 10^{-2}$ & $4.1 \times 10^{-2}$ \\
\hline & & & 6 & 6 \\
\hline & & $\begin{array}{c}\text { Vol ume } \\
\left(m^{3}\right)\end{array}$ & 1000 & 1000 \\
\hline \multirow[t]{3}{*}{$\begin{array}{l}\text { GT-2B } \\
\text { Vent }\end{array}$} & & $\begin{array}{l}\text { Flow rate } \\
\left(\mathrm{m}^{3} / \mathrm{s}\right)\end{array}$ & $1.3 \times 10^{-2}$ & $0.69 \times 10^{-2}$ \\
\hline & & $\begin{array}{l}\text { Duration } \\
\text { (h) }\end{array}$ & 6 & 36 \\
\hline & & $\begin{array}{l}\text { Voi ume } \\
\left(\mathrm{m}^{3}\right)\end{array}$ & 340 & $>950$ \\
\hline \multicolumn{2}{|l|}{ Water Loss } & $\begin{array}{l}\text { Fraction } \\
\text { of } \\
\text { injected } \\
\text { volume }\end{array}$ & 0.6 & $<0.1$ \\
\hline
\end{tabular}

In this section we discuss the following:

- Event rate history.

- Event rate vs EE-1 pressure.

- Map of larger events as recorded in GT-2B.

- S-P delay histories for selected events as recorded at each station.

- Signal-amplitude vs signal-duration study.

- Cumulative number of events vs signal-magnitude study.

The downhole monitoring systems were similar to those used in previous experiments (Refs. 4-7) as was most of the recording equipment. The events were recorded and monitored by the following equipment: 
- Tape recorder.

- Two Hewlett-Packard 8-pen strip recorders that displayed the surface seismic net output, the output from six geophones, and the EE-1 pressure.

- Biomation scanning of horizontal geophone output from both stations, which produced plots of selected events in real time during the experiment.

The tape recordings and strip recorders had WWV channels for accurate time basing. The analogue tapes were used later to produce both digital tapes containing the larger events and continuous oscilloscope strip charts containing the filtered ( $100 \mathrm{~Hz}$ High Pass) output from selected geophone channels. The digital tapes were then used in the production of the event maps by techniques described in earlier reports (Refs. 4-6). The strip charts that contained the least noisy horizontal-geophone component from each station, along with the WWV time code, were examined for all events that appeared to be seismic in nature and that were recorded at each station. The peak-to-peak maximum amplitudes were measured for all signals on one channel for several half-hour periods along with the signal time duration (measured from signal onset to estimated time at which the signal disappeared into the background) for a number of events (spanning the range of observed amplitudes). The results are presented below.

\section{A. Event Rate History and Event Rate vs Pressure}

Estimates of the rate of events were obtained from the Hewlett-Packard strip chart at various times during the pressurization and subsequent shut-in. Figure 10, which is similar to Fig. 1 except for the superposition of microseismic event rate, shows an increasing event rate with time until the cessation of pumping into EE-1, at which time the rate drops sharply. Figure 11 plots these same event rates against the EE-1 pressure. Judging by the pressure at the commencement of activity and the pressure at the sharp increase in activity, this plot seems to indicate a threshold for seismic activity between 9.5 $\mathrm{MPa}(1400 \mathrm{psi}$ ) and $11.0 \mathrm{MPa}$ (1600 psi), along with another apparent critical pressure of $15.0 \mathrm{MPa}(2200 \mathrm{psi})$ at which seismic activity increases sharply. Examination of the EE-1 pressure history in either Fig. 1 or 10 shows a constant pressure level at this last pressure during the last $2 h$ of pumping, indicating the onset of further hydraulic fracturing. Additional fracturing was confirmed by the tracer experiments performed before and after 
SUE. As explained later, the modal volume of the fracture system increased by about $40 \%$ as a consequence of SUE. Better measurements of the event rate using the oscillograph recordings should be useful in further examination of these relations.

B. Map of Events Recorded at the GT-2B Station

The initial map showing a plan view of 150 selected events recorded in GT-2B is shown in Fig. 12. The GT-2B geophone events were selected because this station contained dual inclinometers whose output allowed orientation of the geophone array. The locations of the seismic stations and the injection zone in EE-1 are also indicated. We located events during this experiment using a new location technique utilizing the S-P times and the relative delays measured in EE-2 along with the azimuths of the events recorded by the GT-2B geophones. Because we knew the azimuth measured from the GT-2B geophones and the distances from both geophone packages, GT-2B and EE-2, we could measure dips without actually using the output of the vertically oriented geophones. This follows because knowing the azimuth and radial distance with respect to GT-2B defines a unique circle in three-dimensional space. Knowing only the distance from EE-2 defines a sphere. Intersections of the circle and the sphere define only two possible points in space. We were able to eliminate one of these two possible locations by comparing the azimuth recorded at GT-2B with the relative polarization direction recorded by the EE-2 geophones. The complete geometrical location of the microseismic events without the vertically oriented geophones was fortunate because the vertical geophones may not have been working properly due to large inclinations of both wells from the vertical.

Figure 13 shows event locations from three previous experiments, Expts. 203, 195, and Run Segment 4, projected in plan view. Fracturing experiments 203 and 195 were conducted on March 14, 1979 and March 21, 1979, respectively. The microseismic events during the 1-day experiments, 203 and 195, are confined to a fairly narrow zone that trends in the north-northwest direction, but the events measured several days after the beginning of Run Segment 4 indicate considerable lateral departure from this narrow zone, caused by additional diffusion of the injected water. Figure 14 shows the plan views of the SUE microseismic events sequenced in time, in nearly $1-h$ increments. In examining these sequences it should be recalled from Fig. 10 that pressurization began about 16:00. As can be seen, the north-by-northwest-trending seismic 


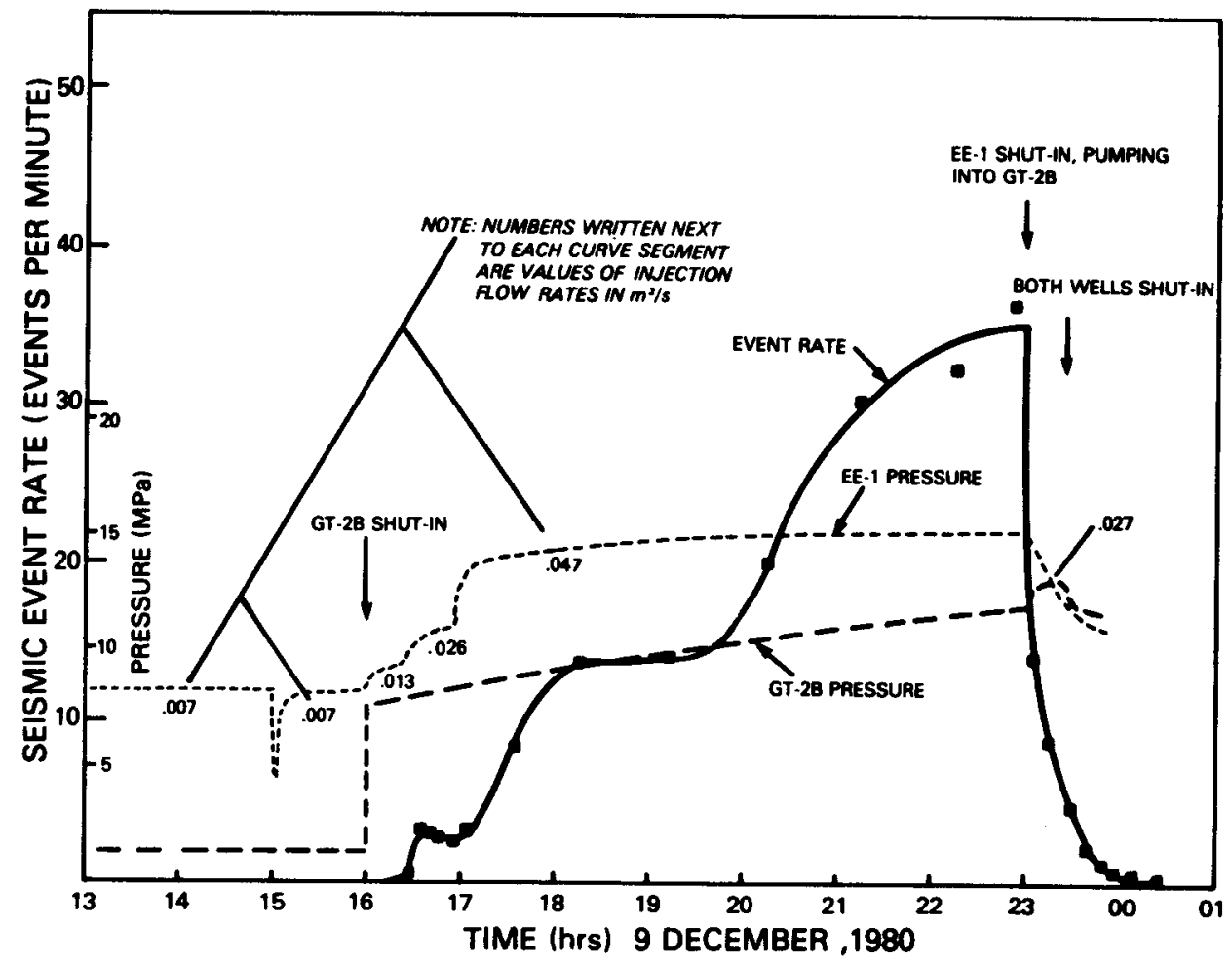

Fig. 10 .

System pressures, pumping rates, and seismic event rates during SUE.

EE-1 PRESSURE (PSI)

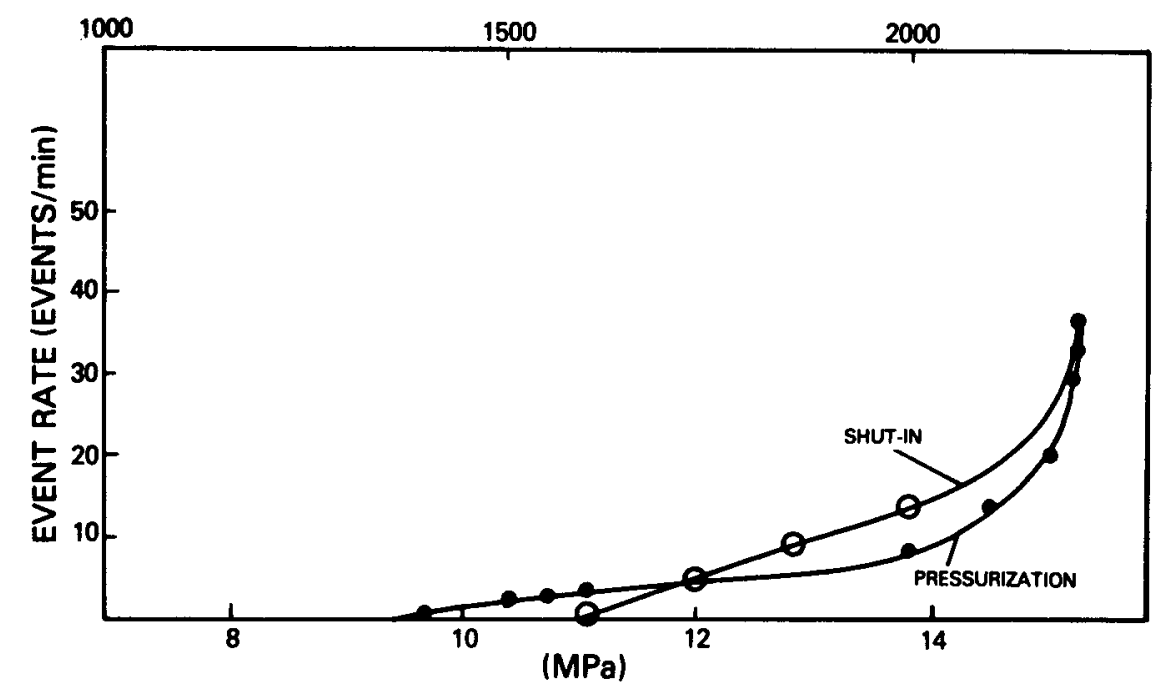

Fig. 11.

Seismic event rate as function of $E E-1$ wellhead pressure. 
zone, so prominant during experiments 203 and 195, is still apparent in the SUE data, but there is some tendency for the microseismic events to spread laterally--in the last sequence, from 22:09 to 23:10, this spreading amounts to about $200 \mathrm{~m}$. Figure 15 shows the events projected on a vertical northsouth-trending plane. Most of the events are concentrated within a circular zone with an area of $60000 \mathrm{~m}^{2}$. As discussed in the report on Run Segment 5 (Ref. 1), the seismic area so determined in SUE is in qualitative agreement with heat-transfer areas determined by modeling the thermal drawdown of the reservoir.

C. S-P Delay Histories For Selected Events

Further reduction of the data on the analogue tapes is still being processed to provide measurements of the $P$ - and $S$-wave delay as measured at each station. These measurements, along with measurements of the S-P delay at the EE-2 station, should remove most of the ambiguities arising from centrosymmetry as described in Ref. 6. However, a series of playbacks were obtained from the Biomation digital oscilloscope during the pressurization. An example is shown in Fig. 16 in which the two horizontal channels for each station are displayed. An approximate S-P delay was easily obtained for most of these randomly selected events, and Figs. 17 and 18 show the changes in these delays with time in GT-2B and EE-2, respectively. The envelope for each group provides a rough measure of the movement of the events relative to both stations. D. Signal Amplitude vs Signal Duration Study

In statistical studies of sequence of seismic events the usual parameter against which the frequency or cumulative number of events is plotted is the local magnitude, $M_{L}$. The local magnitude scale is defined, Ref. 8:

$$
M_{L}=2.79 \log T-3.63,
$$

where $T$ is the signal duration in seconds. The signal duration is, however, difficult and tedious to measure and therefore a relation between the duration and maximum peak-to-peak amplitude as measured on the strip chart has been developed. This relation is based upon the SUE data, using initially determined values of T. Figure 19 shows a plot of these data accompanied by the best power curve fit to the data. This curve has the equation 


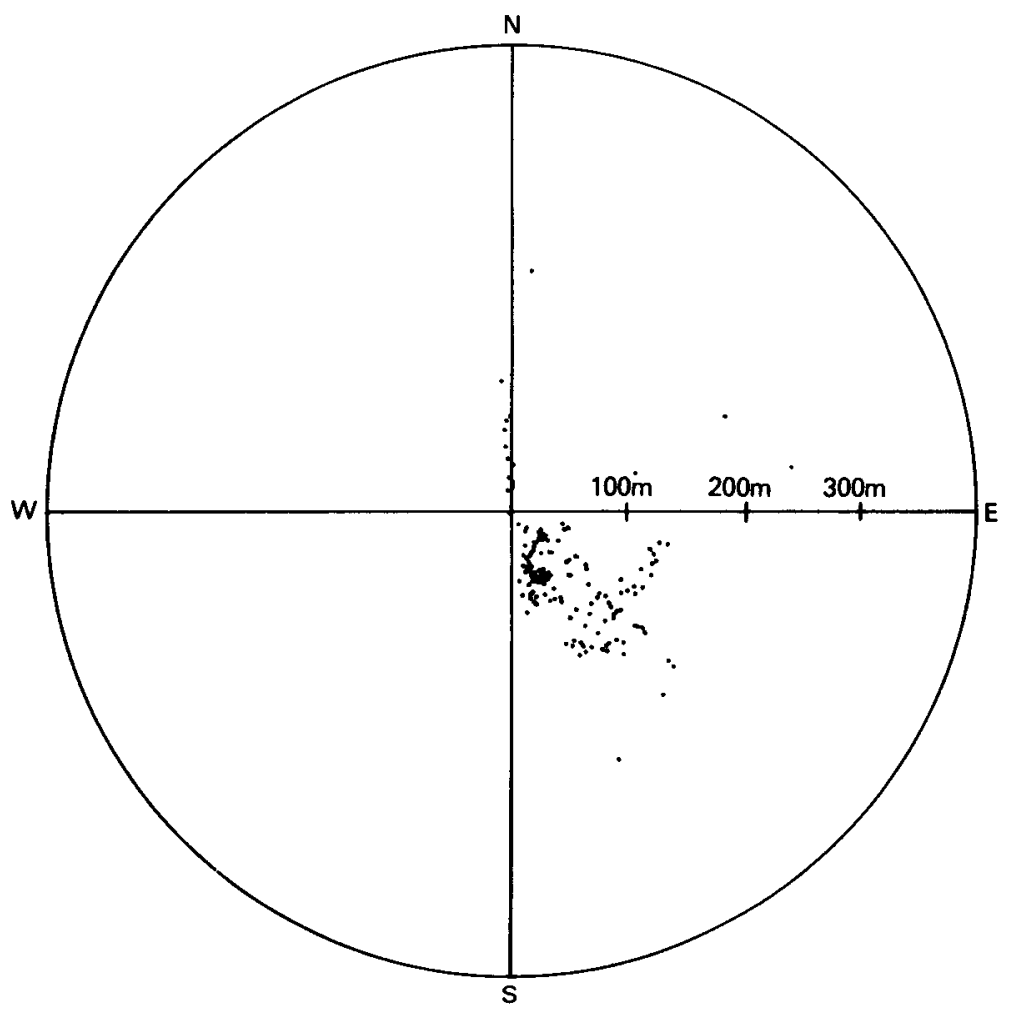

Fig. 12.

llap (plan view) of seismic events recorded at the GT-2B station.

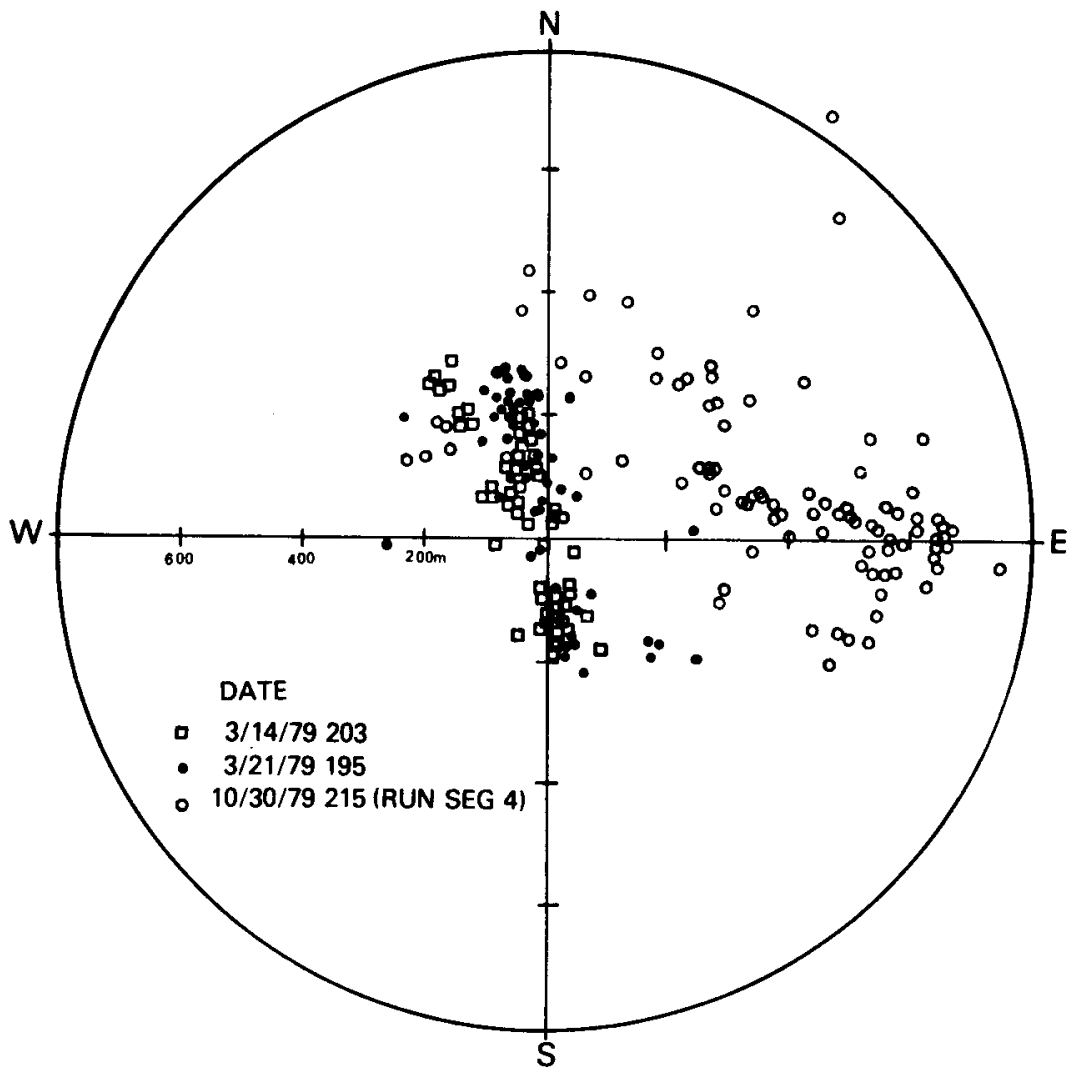

Fig. 13 .

Map (plan view) of seiśmic events located during previous Expts. 195, 203, and 215. 

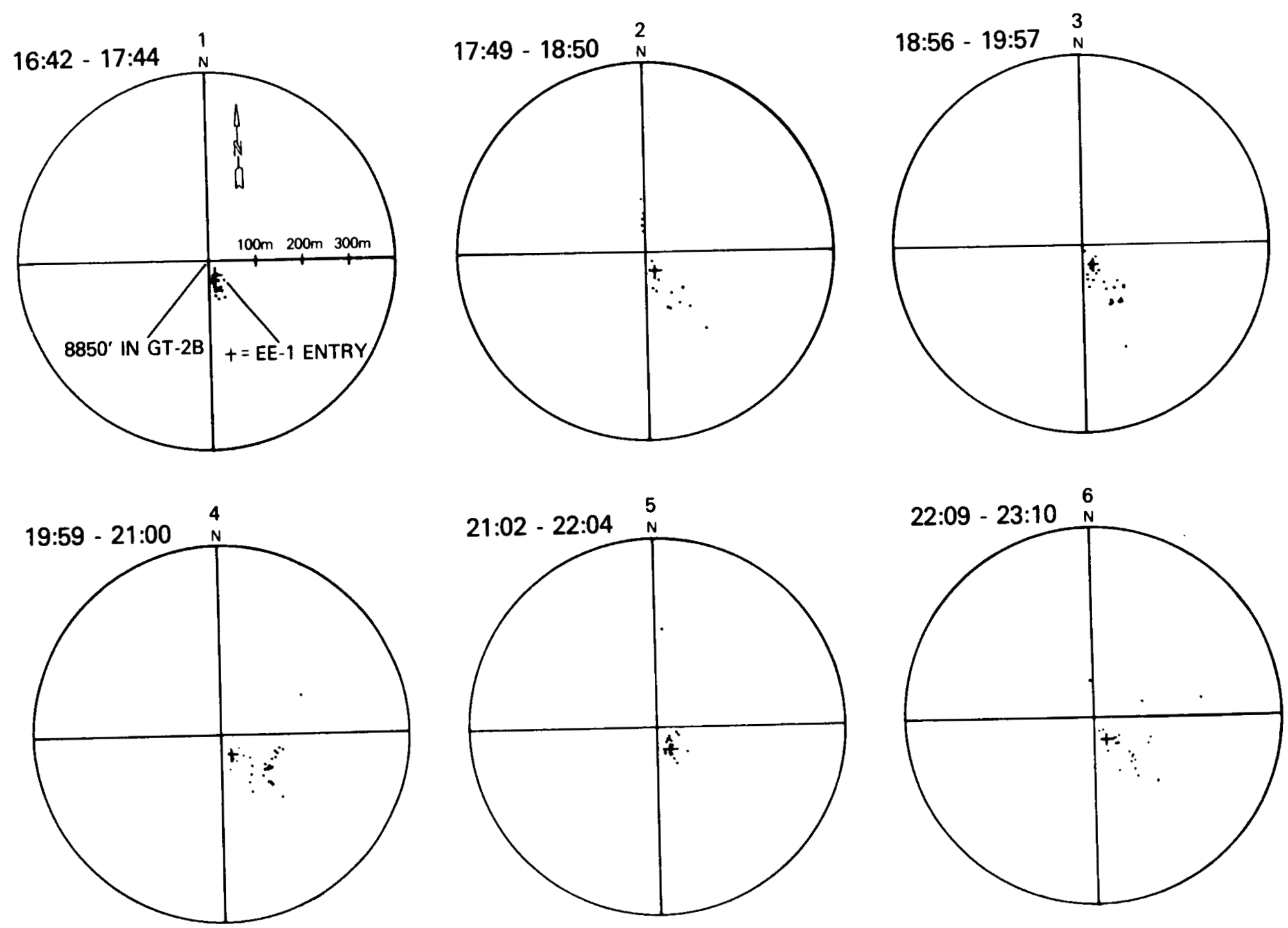

Fig. 14.

Maps (plan views) of seismic events located in six equal-time intervals during the EE-1 and GT-2B injections of the SUE experiment. 


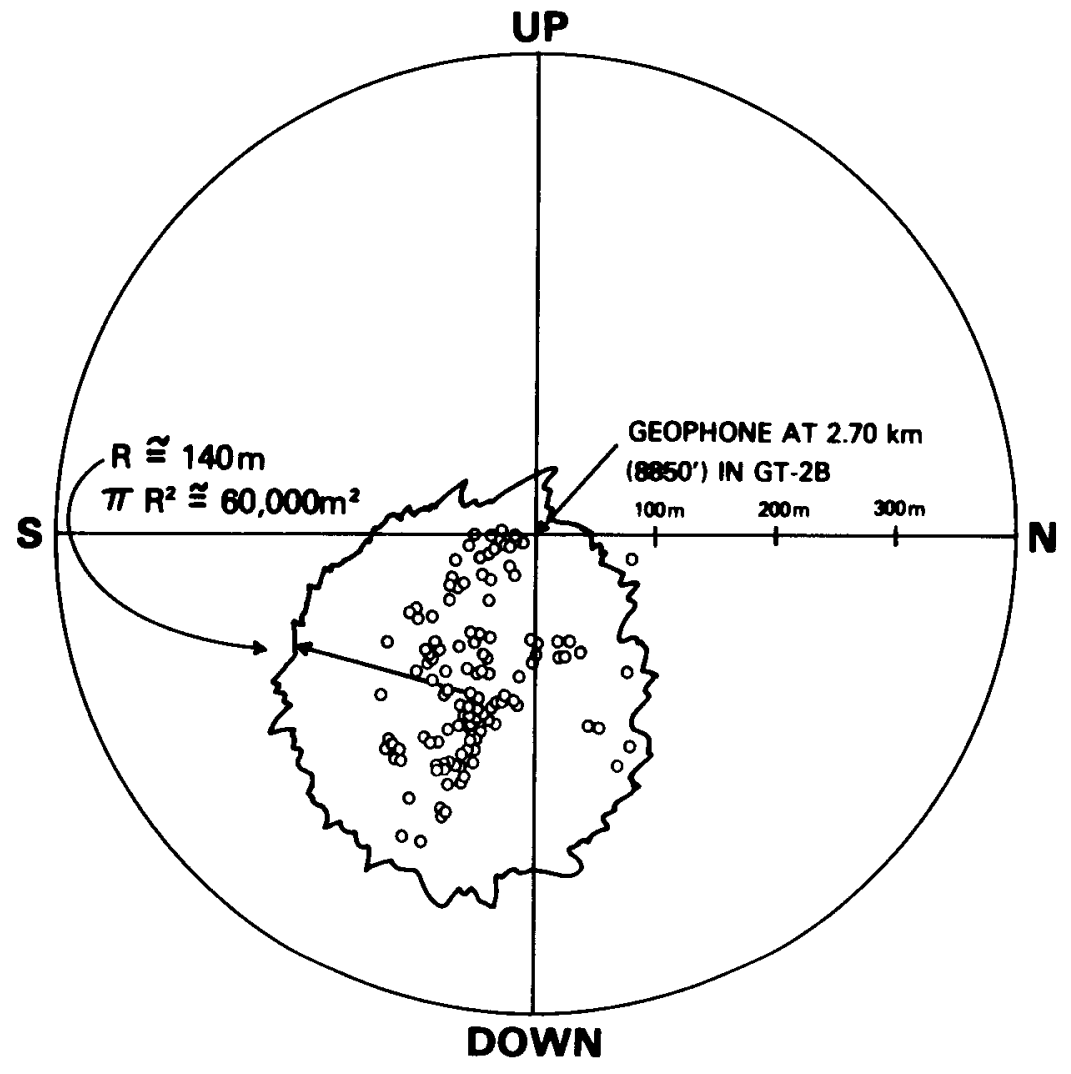

Fig. 15.

Elevation view of SUE events recordea at GT-2B. Events are projected on a vertical, north-south-trending plane.

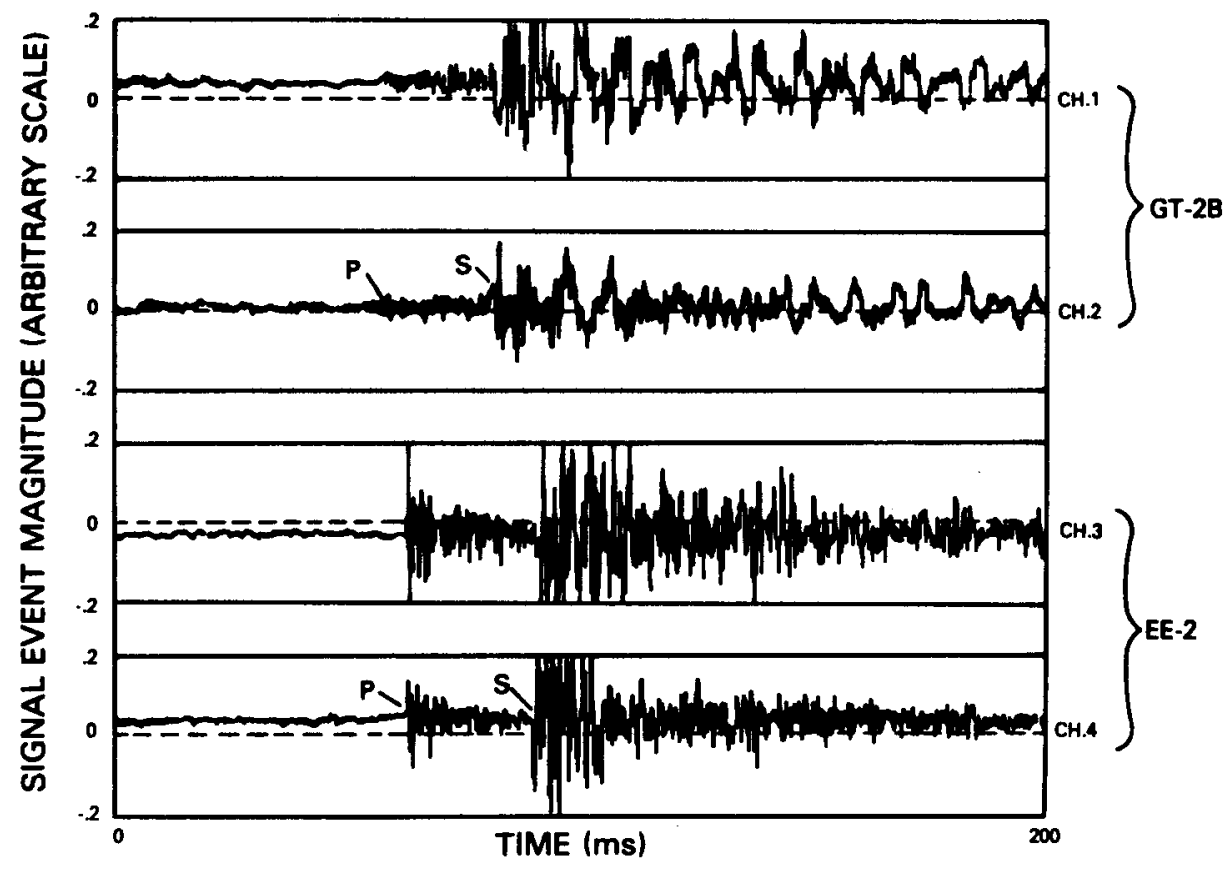

Fig. 16 .

Biomation digital oscilloscope playback showing the characteristics of a typical microseismic event as received on the horizontal geophone. 


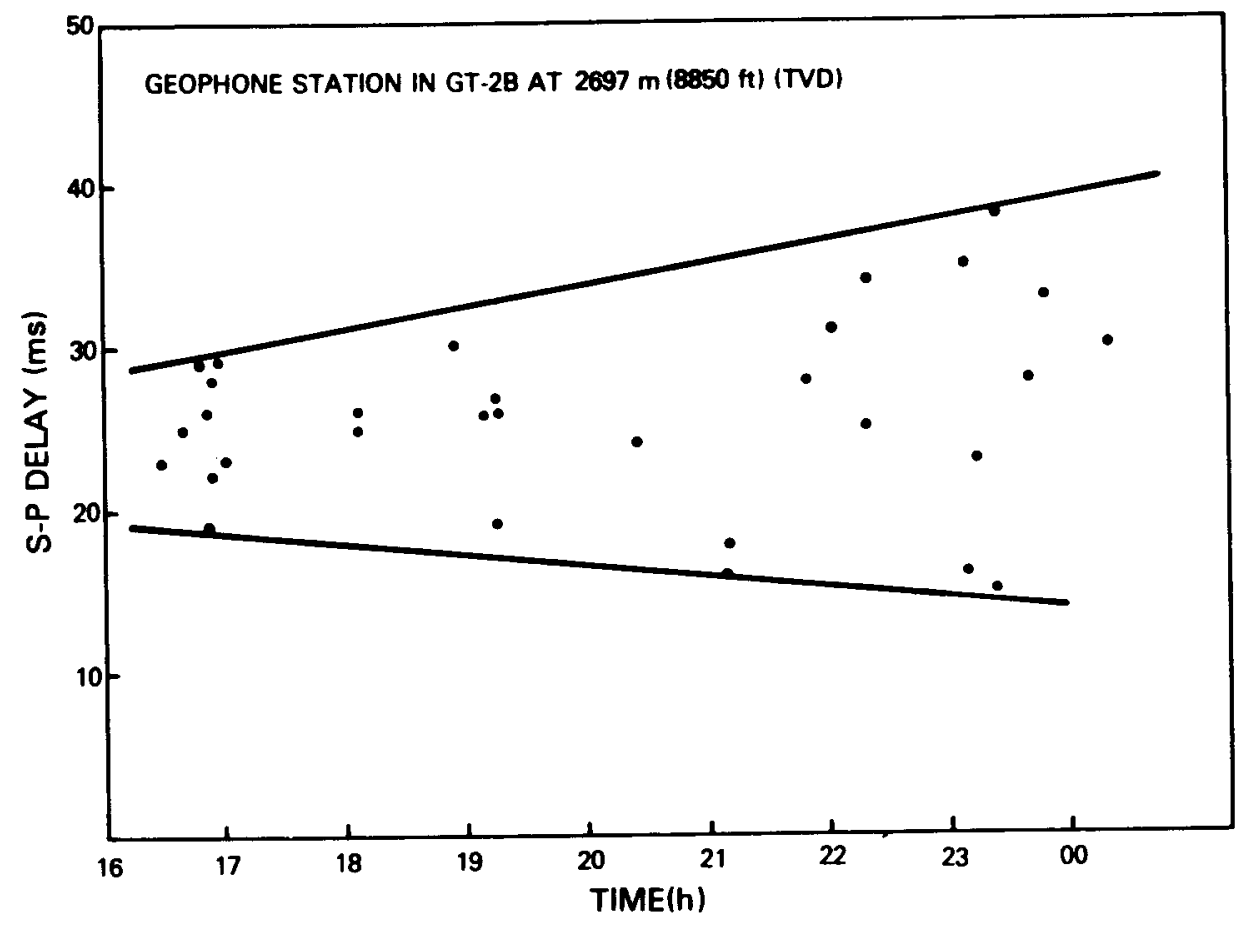

Fig. $1 \%$

Envelope of $S-P$ delay times for events receiveo at $G T-2 B$ vS time.



Fig. 18 .

Envelope of S-P delay times for events received at tE- 2 vs time. 


$$
A=65.6 T^{1.82} \text {, }
$$

where $A$ is the peak-to-peak chart amplitude in $\mathrm{mm}$.

Combining the two equations gives the local magnitude as a function of the measured amplitude:

$$
M_{L}=1.54 \log A-6.42 \text {. }
$$

This equation is used below in determining the amplitude range for a given magnitude interval.

\section{E. Cumulative Number vs Signal Magnitude Study}

Figure 20 shows a portion of the oscillograph record on which numerous seismic signals of varying amplitude are present. To avoid spurious signals due to geophone package movement in the wells, the amplitudes were measured only for those signals present on the EE-2

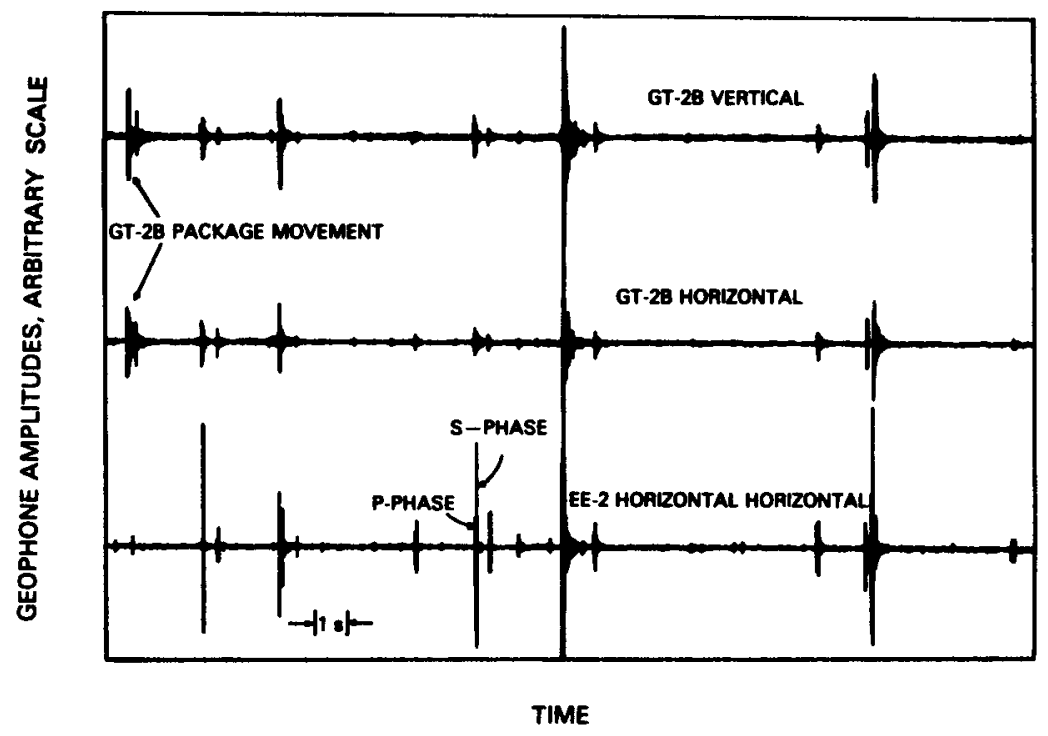

Fig. 20 .

Typical portion of oscillograph output of filtered analogue tape data recorded from components in GT-2B and EE-2. 
horizontal-geophone channel that had nearly simultaneous signatures on the GT-2B horizontal channel. The number of signals with amplitudes bounded by values computed from Eq. (5) for magnitude intervals of 0.25 were tabulated over the magnitude range -6.25 to -3 and for a given time interval (typically $0.5 \mathrm{~h}$ ). Figure 21 shows the $\log$ of the cumulative sum (number of events with magnitudes greater than a given magnitude) vs magnitude for three time intervals during the EE-1 injections. Typically normal seismic sequences show similar linear plots with slopes (the so-called b-values) ranging from -0.5 to -1.5 ; our $b$-values range from only -0.62 to -0.65 . Of interest is the major change in the relative number of large events as indicated by the departures in each of the lines in Fig. 21 that start at a magnitude of about -3.5. 0f even greater interest is the energy of these larger events (say those with $M_{L}$ $>-3)$. Using the energy-magnitude relation defined by Richter (9) the relative energies for each time interval were computed and are shown in Table II.

Even though the reservoir was continually being stressed to higher levels, the production of the larger events took a dramatic drop along with released energy during the later stages of pumping. This suggests that these events were associated with the thermally drawn-down region of the reservoir and that most of this stored strain had been released by the initial pressurization.

IV. PRESSURE OSCILLATIONS

Analytical models (Refs. 10 and 11) and experimental results (Ref. 12) suggest that both free and forced oscillations of the pressure in a HDR system can yield information about fracture size or impedance. During the EE-1 and GT-2B high-pressure injection-phases, valve operations and piston pump strokes

TABLE II

RELATIVE ENERGIES

\begin{tabular}{|c|c|c|c|c|}
\hline Time Interval & $\frac{\text { Pressu }}{\underline{\mathrm{EE}-1}}$ & $\frac{(\mathrm{MPa})}{\mathrm{G} \bar{T}-2 \mathrm{~B}}$ & $\begin{array}{l}\text { Number of Events with } \\
\text { Magnitude }>-3\end{array}$ & $\begin{array}{l}\text { Relative } \\
\text { Energy } \\
\end{array}$ \\
\hline $17: 00-17: 30$ & 13.3 & 5.6 & 4 & 1 \\
\hline $19: 00-19: 30$ & 14.8 & 10.1 & 10 & 19 \\
\hline $22: 09-22: 39$ & 15.2 & 11.6 & 2 & 5 \\
\hline
\end{tabular}


(a) TIME DURATION 17:00-17:30

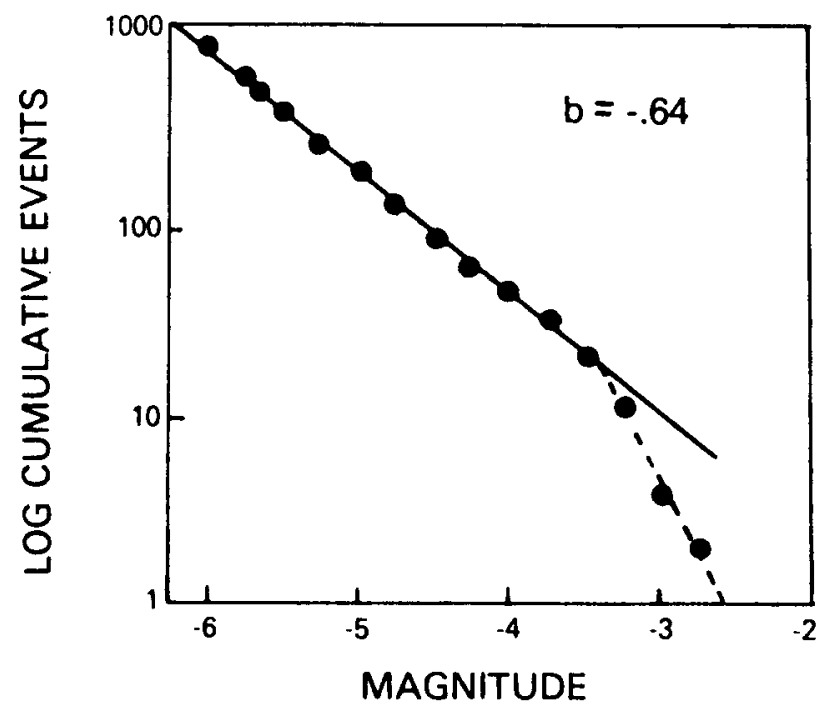

(b) TIME DURATION 19:00-19:30

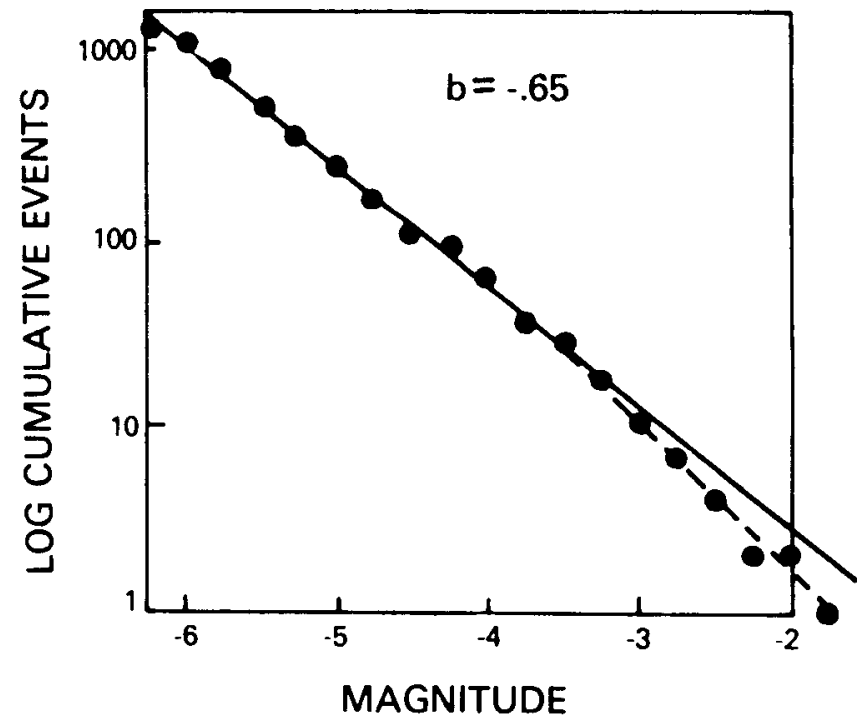

(c) TIME DURATION 22:09-22:39

Cumulative frequency vs local magnitude plots for EE-2 station data.

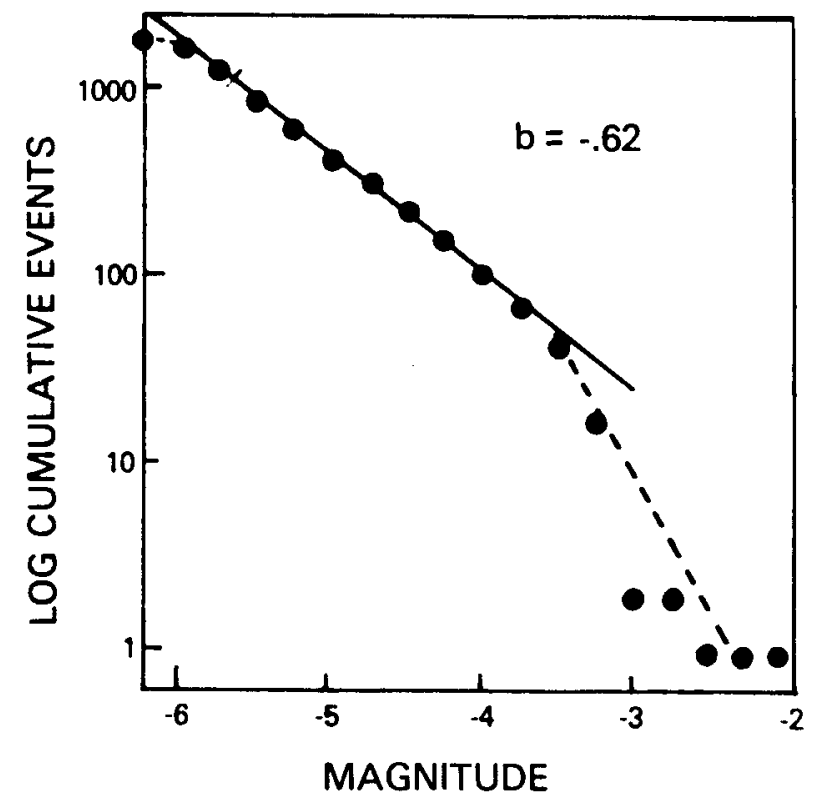


could stimulate such oscillations. Therefore arrangements were made to record and monitor possible oscillations. Both the wellhead pressures of GT-2B and EE-1 and the amplified oscillations of the wellhead pressures about their mean values were recorded by chart-recorder and on magnetic tape (Ampex FR 3020).

Oscillations of the wellhead pressures were observed in two different frequency ranges:

(1) Between 2 and $30 \mathrm{~Hz}$ the Halliburton pumps produced very narrowbanded noise with pressure amplitudes of about 1 bar at the wellhead of EE-1. Changes in the pertinent line spectra are mainly due to changed flow rates. It is hard to tell if the remaining differences within the same flow-rate interval are caused by changes in reservoir spectral response (which might be due to altered fracture size or inlet impedance) or by varying pump operation (Fig. 22). In this frequency range no signal above noise level was transmitted through the reservoir to the GT-2B wellhead.

(2) Shut-ins, decreases of flowrate, venting, and other valve operations triggered damped harmonic oscillations in the frequency range between 0.1 and $0.3 \mathrm{~Hz}$. They are believed to be longitudinal (compressional) oscillations of the water in the wellbore. Their natural frequencies appear to be those of a fundamental mode oscillation, implying that the inlet depth corresponds to a quarter of a wave length. The wellhead was shut in for all the observed cases, so the water was displaced from the borehole into the reservoir and back again.

The damping of these oscillations may be due to the viscosity of the water column, but could also contain information about changes of inlet impedance. However, there is no significant change in the damping constants of the observed oscillations

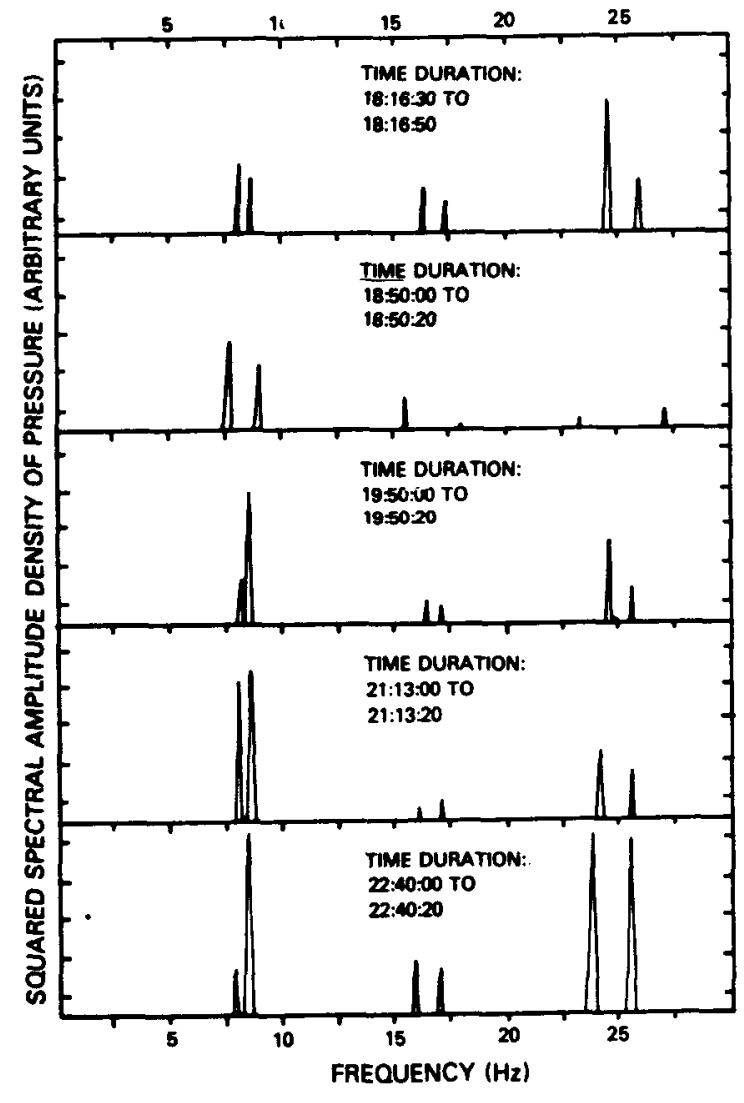

Fig. 22 .

Spectral analysis of pressure oscillations during EE-1 injections. 
(Fig. 23). These oscillations were mainly stimulated in the wellbore where the valve operations were performed, but with two exceptions: the switching from Los Alamos pumps to Halliburton pumps at the EE-1 wellhead caused an oscillation in GT-2B, and the beginning of the vent of GT-2B triggered one in $\mathrm{EE}-1$.

(3) During the venting of GT-2B, a long-period oscillation with a period of $454 \pm 2 \mathrm{~s}$ was observed for $3 \mathrm{~h}$. The pressure deviations were nonharmonic but the frequency was constant, that is, independent of pressure. At first it was thought that this constant-frequency response might be due to elastic opening and closing of the fracture system, but eventually it was attributed to a pressure-activated control valve. The failure of two pressure regulators in the supply line to the control valve, FCV-2, resulted in the control valve's fluctuating, with the normal pressure fluctuations produced by the air compressor.

\section{POST-SUE IMPEDANCE MEASUREMENT}

As mentioned in the introduction, following the vent from the highpressure levels during SUE, normal Run Segment 5 loop operations were resumed at 06:20 on December 10, and continued until 09:00 on December 16. This period of loop operation provided an opportunity for measuring the post-SUE reservoir impedance. This measurement differs from the impedance estimates in Sec. II in that quasi-steady conditions prevailed for several days. The quasi-steady measurement is the one we usually measure, and a post-SUE measurement under these quasi-steady conditions was desired for comparison to the one obtained before SUE.

Figure 24 shows the overall reservoir impedance history just before and just after SUE. The total impedance involves a buoyancy correction that was calculated to be $2 \mathrm{MPa}(300 \mathrm{psi})$. The entrance and exit impedances are derived from shut-in experiments on the dates shown. The techniques for determining entrance and exit impedances are based upon Muskat analysis of the wellhead pressures during shut-ins of EE-1 and GT-2B, respectively. Background discussion of this type of analysis is found in Ref. 7, and the complete 

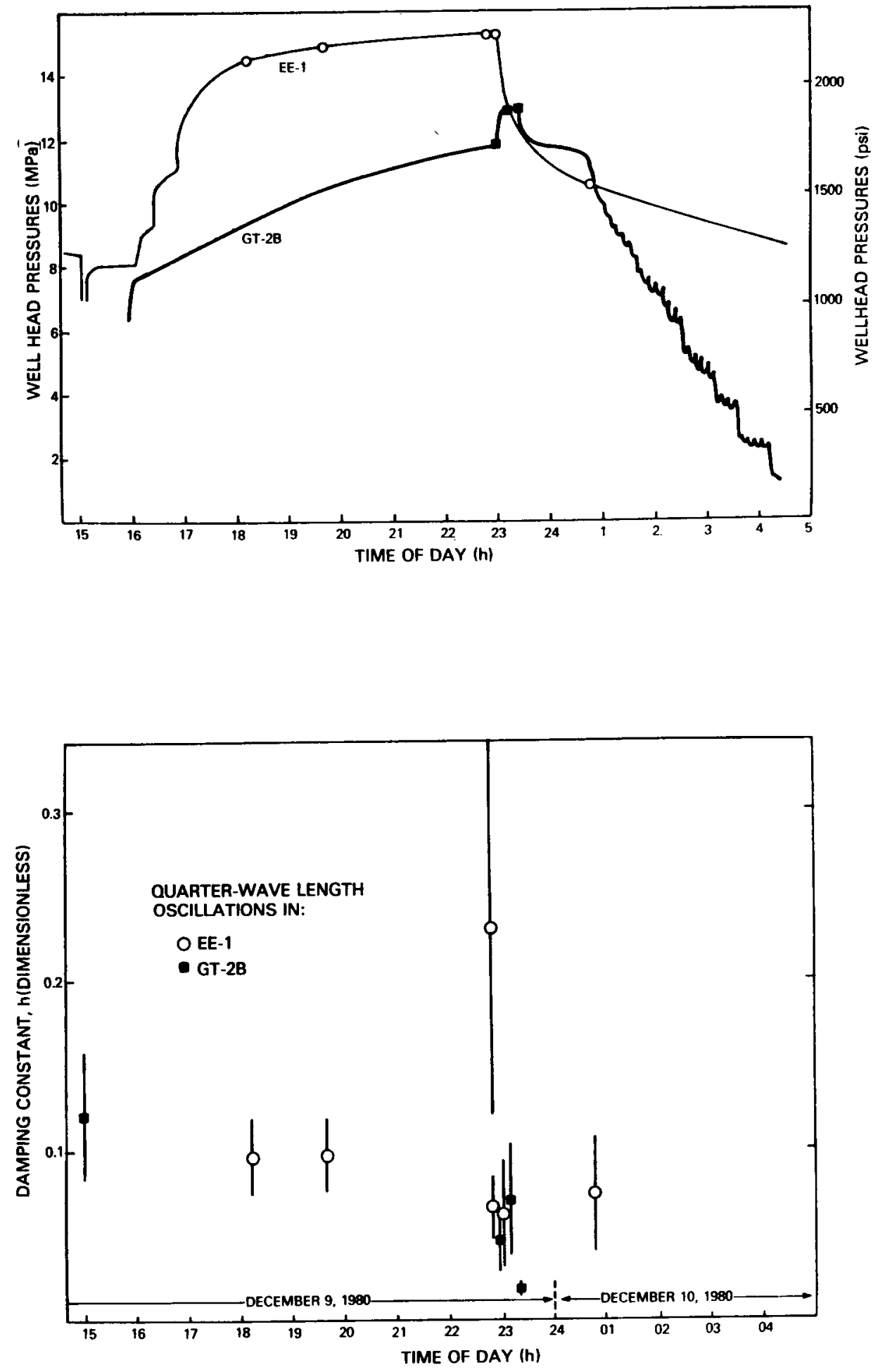

Fig. 23.

Damping constants of oscillations in the boreholes. 


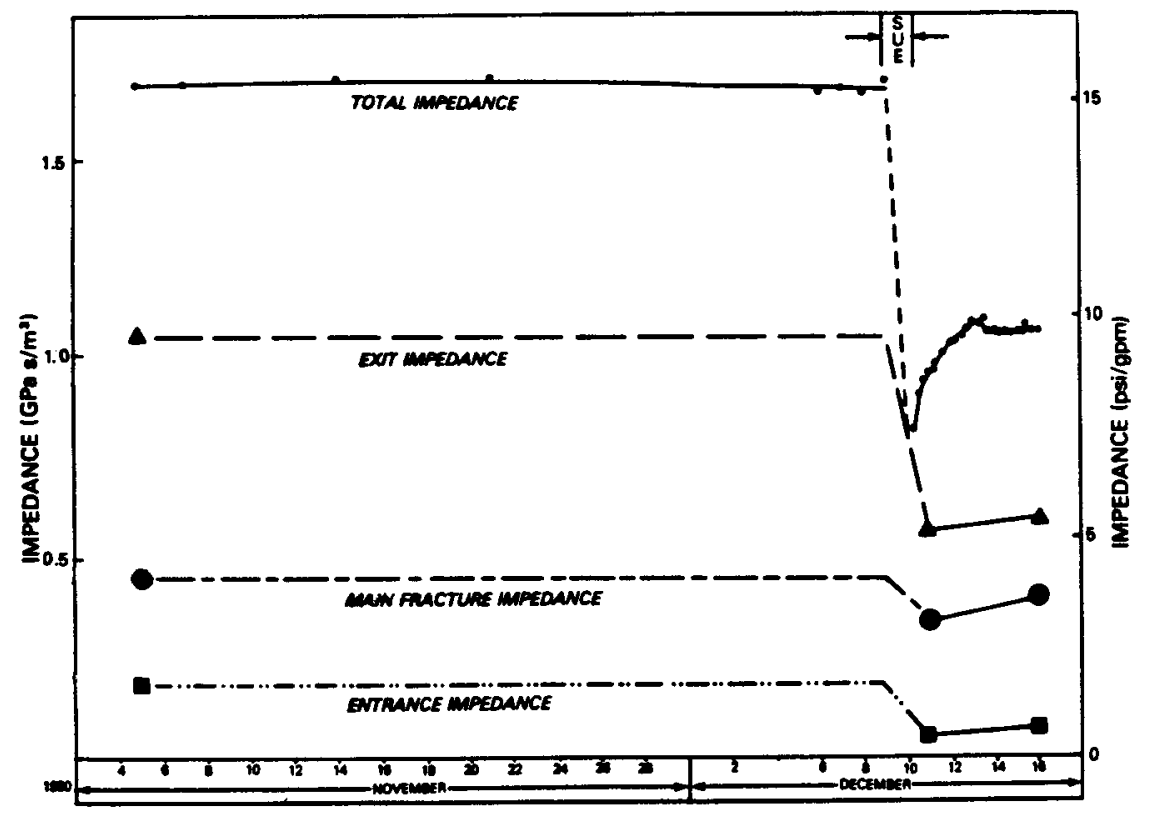

Fig. 24 .

Effect of Stress Unlocking Experiment (SUE) on impedances.

details of all the Run Segment 5 shut-ins, before and after SUE, are presented in an internal technical report.*

The results of the experiment are summarized in Table III, which shows the percentage decrease in the impedance values.

TABLE II I

CHANGES IN IMPEDANCES CAUSED BY SUE

(a)

$$
\text { Before, GPa }
$$

Type of Impedance

Total

Entrance

Exit

Main Fracture $\mathrm{s} / \mathrm{m}^{3}$ (psi/gpm)

1.42

(15.5)

0.16

0.90

0.38

(b)

After, GPa $\mathrm{s} / \mathrm{m}^{3}$ (psi/gpm)

0.90

(9.8)

$0.06 \quad(0.7)$

$0.50 \quad(5.5)$

$0.34 \quad(3.7)$
Percent Decrease $(a-b) / a \times 100$

ÆR. L. Aamodt, "Distributed Impedances in the EE-1/GT-2B Circulation System During Run Segment 5 (Phase 1, Experiment 217) As Determined From Shut-in Experiments," Los Alamos National Laboratory internal report Tech Memo \#1, January 23, 1981. 


\section{TRACER STUDIES}

In order to characterize the changes in fracture-system volume and flow distribution produced by the SUE experiment, radioactive $\mathrm{NH}_{3} \mathrm{Br}$ (2) tracer experiments were conducted before and after the SUE. In both cases, a 400-mCi pulse of tracer was injected and was monitored by logging with a downhole gamma counter in addition to counting at the production wellhead with a $\mathrm{NaI}$ crystal detector. The pre-SUE tracer test was run on necember 2, 1980, and the post-SUE tracer test occurred on December 12, 1980.

Flow conditions and preliminary results of these tests are compared in Table IV with other tracer experiments, using Na-Fluorescein dye, as well as radioactive $\mathrm{Br}$ tracers during Run Segments 4 and 5 . In this table, only the modal volume is presented for comparison. Previous presentations of the tracer results (Ref. 7) have also compared the integral mean volume. However, as is shown in the last column of Table IV, for several tracer experiments the sampling was terminated before background was reached, and the integral mean volumes include varying amounts of the long residence-time data. Because of equipment malfunction, the data for the pre- and post-SUE experiments were recorded by hand at roughly $1-h$ intervals. Unfortunately, data for the $6-h$ period centered at about the modal volume in the pre-SUE experiment was not recorded. The modal value presented in Table IV was found by superimposing the data measured downhole with the data measured at the surface. The mode of the downhole data was then adjusted for the transit time to the surface to give the mode in the surface data.

Comparison of the modal volumes from the segments 4 and 5 experiments show a regular increase of the modal value with time. This increase in volume is attributed to thermal contraction effects due to heat extraction and is analyzed in more detail below. A rather large change in the modal volume is observed in Fig. 25 after the pressurization of the system during SUE. The high injection pressure of $15 \mathrm{MPa}$ (2200 psi) was sufficient to increase the modal volume from 187 to $266 \mathrm{~m}^{3}$, a $43 \%$ increase in size. Comparison of the normalized residence time distributions for the last 3 tracer experiments (not presented here) shows no corresponding change in dispersion characteristics due to the SUE experiment. Apparently the volumes of the existing fractures were increased with no new fractures or other changes in flow paths being created. Detailed studies of these effects will be considered in a subsequent report. 
TABLE IV

SUMMARY OF DYE AND RADIOACTIVE TRACER EXPERIMENTS

\begin{tabular}{|c|c|c|c|c|c|c|c|c|c|}
\hline $\begin{array}{l}\text { Experiment } \\
\text { and Date } \\
\end{array}$ & Tracera & $\begin{array}{l}\text { EE-1 } \\
\text { Injection } \\
\text { Pressure } \\
\mathrm{MPa} \\
\end{array}$ & $\begin{array}{l}\text { GT-2B } \\
\text { Produc- } \\
\text { tian } \\
\text { Pres- } \\
\text { sure } \\
\text { MPa } \\
\end{array}$ & $\begin{array}{l}\text { GT-2B } \\
\text { Produc- } \\
\text { tion } \\
\text { Flow } \\
\text { Rate } \\
\left(\mathrm{m}^{3} / \mathrm{s}\right)\end{array}$ & $\begin{array}{l}\text { Average } \\
\text { Production } \\
\text { Tempera- } \\
\text { ture } \\
\left({ }^{\circ} \mathrm{C}\right)\end{array}$ & $\begin{array}{l}\text { Cumulative } \\
\text { Power Ex- } \\
\text { tracted Dur- } \\
\text { ing each Run } \\
\text { Segment } \\
\left(10^{6} \times b-h\right) \\
\end{array}$ & $\begin{array}{l}\text { Moda })^{c} \\
\text { Volume } \\
\left(m^{3}\right)\end{array}$ & $\begin{array}{c}\text { Integral } \\
\text { Mean } \\
\text { volume } \\
\left(\mathrm{m}^{3}\right) \\
\end{array}$ & $\begin{array}{l}\text { Total } \mathrm{Pr} \\
\text { duced } \mathrm{Vo} \\
\text { During } \\
\text { Tracer } \\
\text { Test } 1 \mathrm{~m}^{3}\end{array}$ \\
\hline \multicolumn{10}{|l|}{ Run Segment 4} \\
\hline $10 / 26 / 79$ & $\mathbf{f}$ & 17.2 & 1.1 & 0.0064 & 153. & 0.1 & 136. & 207 & 469 \\
\hline $10 / 29 / 79$ & $\mathbf{F}$ & 17.2 & 10.3 & 0.0081 & 154. & 0.3 & 144. & 230 & 619 \\
\hline $11 / 2 / 79$ & $\mathbf{F}$ & 9.3 & 1.1 & 0.0066 & 153. & 0.6 & 121. & 262 & 570 \\
\hline $11 / 12 / 79$ & $\mathbf{F}$ & 9.3 & 1.1 & 0.0064 & 153. & 1.3 & 129. & 283 & 662 \\
\hline \multicolumn{10}{|l|}{ Run Segment 5} \\
\hline $4 / 15 / 80$ & $\mathbf{F}$ & 9.8 & 1.3 & 0.0075 & 158. & 1.6 & 155. & 404 & 1440 \\
\hline $5 / 9 / 80$ & B & 9.5 & 1.3 & 0.0071 & 158. & 2.8 & 161. & 1100 & 3030 \\
\hline $9 / 3 / 80$ & B & 8.8 & 1.3 & 0.0070 & 154 & 7.5 & 178. & 1511 & 4140 \\
\hline $\begin{array}{c}12 / 2 / 80 \text { (Pre- } \\
\text { SUE) }\end{array}$ & B & 8.5 & 1.1 & 0.0065 & 149. & 11.1 & 187. & 581 & 1310 \\
\hline $\begin{array}{c}12 / 12 / 80 \text { (Post- } \\
\text { SUE) }\end{array}$ & $-B$ & 8.4 & 1.3 & 0.0098 & 149. & 11.4 & 266. & 1118 & 2690 \\
\hline
\end{tabular}

af = Sodium fluorescein dye, $B={ }^{82} \mathrm{Br}$.

breservoir outlet temperature measured downhole.

cmodal volume is defined as the volume of tracer circulated through the fracture system from time of entry until that time at which the tracer concentration at the outlet is maximum. We belleve this volume. to be the most easily measured one, as well as the most unamblguous one for making comparisons of the effect of pressure or temperature or fracture size.

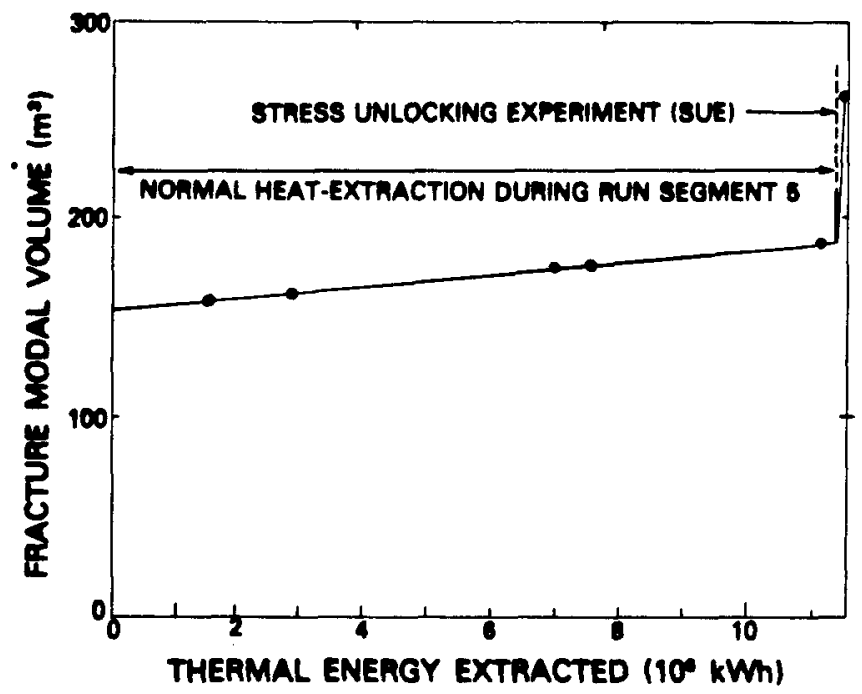

Fig. 25.

Fracture modal volume increases due to Run Segment 5 heat extraction and highpressure injection during SUE. The thermal energy referred to here is limited to that of the reservoir only--it excludes the contribution from the injection and production wellbores. Thus the total energy during Run Segment 5 was $15 \times 10^{6}$ kWh. 
Figure 25 indicates a reasonably linear increase of fracture modal volume as heat was extracted; a total heat extraction, $E$, resulted in a volume increase, $\Delta V$, of $37 \mathrm{~m}^{3}$. The energy $E$ is related to the integral of the temperature decrease over the entire reservoir rock volume affected by thermal drawdown. If the rock is assumed to be a stress-free, freely contracting media, then $\Delta V$ is also related to the same integral, and it can be shown that

$$
\Delta V=\alpha_{v} E /(\rho c)_{r}
$$

where $\alpha_{v}$ is the volumetric thermal expansion coefficient of the rock and $(\rho c)$ is its volumetric heat capacity. Using a typical value, $(\rho \mathrm{c})_{r}=2.7 \times 10^{-6}$ $\mathrm{J} /\left(\mathrm{m}^{3}{ }^{\circ} \mathrm{C}\right)$, and the preceding values of $\Delta V$ and $E, \alpha_{v}$ can be estimated as $2.8 \times$ $10^{-6} /{ }^{\circ} \mathrm{C}$. This is only one-tenth the value typical of laboratory experiments with dense granite (Ref. 13). The large discrepancy is attributed to two causes: (1) the rock is actually under considerable tectonic stress, and much of the expected thermal contraction simply was consumed in relieving a part of these stresses; and (2) much of the thermal contraction may have been manifested as an increase in porosity that occurred far enough away from the main fracture system that the porosity increase was not detected by the tracer passing through the fracture system. It is interesting to note that SUE itself resulted in another $\Delta V$ of $78 \mathrm{~m}^{3}$, so that the total volume increase was $115 \mathrm{~m}^{3}$, still only $30 \%$ of that expected if the reservoir was completely free to contract.

VII. CONCLUSIONS

- The high-pressure phases of SUE resulted in a reduction of overall reservoir impedance by $37 \%$, from $1.42 \mathrm{GPa} \mathrm{s} / \mathrm{m}^{3}$ (15.5 psi/gpm) before SUE to $0.9 \mathrm{GPa} \mathrm{s} / \mathrm{m}^{3}(9.8 \mathrm{psi} / \mathrm{gpm})$ after SUE. Most of the reduction took place at the reservoir exit where the impedance was reduced from 0.90 to $0.50 \mathrm{GPa} \mathrm{s} / \mathrm{m}^{3}$ ( 9.7 to $\left.5.5 \mathrm{psi} / \mathrm{gpm}\right)$.

- High pressure also caused a $43 \%$ increase in fracture-system modal volume, from 187 to $266 \mathrm{~m}^{3}$.

- The substantial reduction in impedance and increase in fracture size has further improved the chance for success in using the Huff-Puff mode of heat extraction. The SUE experiment also indicates that the present system can be operated in the Huff-Puff mode with good flow 
characteristics. That is, the system now has reasonable water losses, high vent volume, and a high venting flow rate.

- The use of two separated geophone stations has significantly increased knowledge of absolute event location and may allow estimation of rock properties such as local acoustic velocity and attenuation. The geophone packages performed superbly throughout SUE.

- The high degree of linearity of the event frequency/magnitude relations measured during this experiment (Fig. 21) strongly suggests that a single seismic mechanism, most likely shear failure, was the cause for the entire event sequence (magnitude range from -7 to -1.5 ).

- The peak in the rate of larger events near the middle of the pumping sequence with an accompanying maximum of energy release is indicative of the release of stored stress, most likely arising from the prolonged thermal drawdown of the reservoirs.

\section{REFERENCES}

1. G. A. Zyvoloski (Ed.), "Evaluation of the Second Hot Dry Rock Geothermal Energy Reservoir: Results of Phase I, Run Segment 5," Los Alamos National Laboratory report LA-8940-HDR (to be published).

2. H. N. Fisher and J.W. Tester, "The Pressure Transient Testing of a ManMade Fractured Geothermal Reservoir: An Examination of Fracture Versus Matrix Dominated Flow Effect," Los Alamos Scientific Laboratory report LA-8535-MS (September 1980).

3 D. W. Brown, (Ed.), "Results of Experiment 186, The High Back-Pressure Flow Experiment," Los Alamos National Laboratory report LA-8941-HDR (to be published).

4. A. G. Blair, J. W. Tester, and J. J. Mortensen, "LASL Hot Dry Rock Geothermal Project: July 1, 1975-June 30, 1976," Los Alamos Scientific Laboratory report LA-6525-PR (October 1976).

5. Laboratory HDR Project Staff, "HDR Geothermal Energy Development Project Annual Report Fiscal Year 1974," Los Alamos Scientific Laboratory report LA-7109-PR (February 1978).

6. M. C. Brown, R. B. Duffield, C. L. B. Siciliano, and M. C. Smith, "HDR Geothermal Energy Project: Annual Report Fiscal Year 1978," Los Alamos Scientific Laboratory report LA-7807-HDR (April 1979).

7. H. D. Murphy, (Ed.), "Preliminary Evaluation of the Second Hot Dry Rock Geothermal Energy Reservoir: Results of Phase 1, Run Segment 4," Los Alamos Scientific Laboratory report LA-8354-MS (May 1980). 
8. G. M. Cremer, R. B. Duffield, M. C. Smith, and M. G. Wilson, "HDR Geothermal Energy Development Project: Annual Report Fiscal Year 1979," Los Alamos Scientific Laboratory report LA-8280-HDR (August 1980).

9. C. F. Richter, Elementary Seismology, (W. H. Freeman, San Francisco, 1958) p. 366.

10. G. Bodvarsson, "Dynamics of Liquids in Subsurface Spaces; Hydroelastic Oscillations and Waves," Report EAR77-23938 for the National Science Foundation, Parts (I) to (IV), Oregon State University, Corvallis, Oregon (1980).

11. G. Fras, "Reconnaisance de Certains Meilieux Rocheux et Théories des Systèmes," Thesis, Institute Nationale Polytechnique de Poulouse, France, 1979.

12. H. Keppler, "Versuche zur Anregung von Schwingungen in einem hydraulisch erzeugten RiBsystem," Bericht der Bundesanstalt fur Geowissenschaften und Rohstoffe, Hannover, Archiv Nr. 86882 (1980).

13. B. J. Skinner, "Thermal Expansion," in Handbook of Physical Constants, S. P. Clark, Jr., Ed., (Geological Society of America, New York, 1966). 